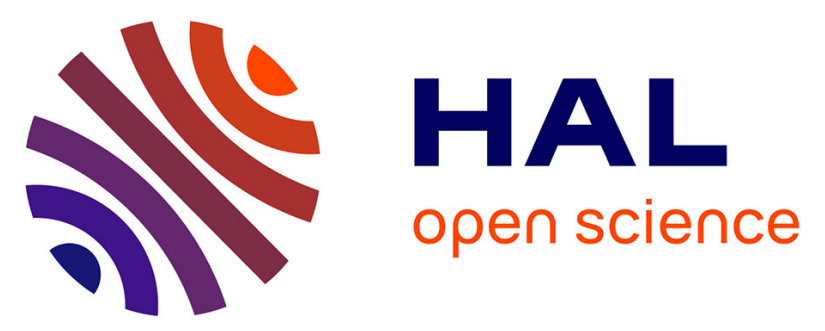

\title{
Advances in the Engineering of Near Infrared Emitting Liquid Crystals and Copolymers, Extended Porous Frameworks, Theranostic Tools and Molecular Junctions Using Tailored Re6 Cluster Building Blocks
}

\author{
Stéphane Cordier, Yann Molard, Konstantin A. Brylev, Yuri V. Mironov, \\ Fabien Grasset, Bruno Fabre, Nikolay G. Naumov
}

\section{To cite this version:}

Stéphane Cordier, Yann Molard, Konstantin A. Brylev, Yuri V. Mironov, Fabien Grasset, et al.. Advances in the Engineering of Near Infrared Emitting Liquid Crystals and Copolymers, Extended Porous Frameworks, Theranostic Tools and Molecular Junctions Using Tailored Re6 Cluster Building Blocks. Journal of Cluster Science, 2015, 26 (1), pp.53-81. 10.1007/s10876-014-0734-0 . hal-01067882

\author{
HAL Id: hal-01067882 \\ https://hal.science/hal-01067882
}

Submitted on 24 Sep 2014

HAL is a multi-disciplinary open access archive for the deposit and dissemination of scientific research documents, whether they are published or not. The documents may come from teaching and research institutions in France or abroad, or from public or private research centers.
L'archive ouverte pluridisciplinaire HAL, est destinée au dépôt et à la diffusion de documents scientifiques de niveau recherche, publiés ou non, émanant des établissements d'enseignement et de recherche français ou étrangers, des laboratoires publics ou privés. 
Advances in the Engineering of Near Infrared Emitting Liquid Crystals and Copolymers, Extended Porous Frameworks, Theranostic Tools and Molecular Junctions Using Tailored $\mathrm{Re}_{6}$ Cluster Building Blocks.

Stéphane Cordier, Yann Molard, Konstantin A. Brylev, Yuri V. Mironov, Fabien Grasset, Bruno Fabre, and Nikolay G. Naumov

S. Cordier, Y. Molard, F. Gasset and B. Fabre

"Institut des Sciences Chimiques de Rennes", UMR 6226 UR1-CNRS, Université de Rennes 1, Campus de Beaulieu 35042 Rennes Cedex, France

Fax : +33223236799

Email: Stephane.cordier@univ-rennes1.fr

K. A. Brylev, Y. V. Mironov, and N. G. Naumov Nikolaev Institute of Inorganic Chemistry, Siberian Branch of the Russian Academy of Sciences, 3 Acad. Lavrentiev pr., 630090 Novosibirsk, Russia Novosibirsk State University, 2 Pirogova str., 630090 Novosibirsk, Russia Email: naumov@niic.nsc.ru 


\title{
Advances in the Engineering of Near Infrared Emitting Liquid Crystals and Copolymers, Extended Porous Frameworks, Theranostic Tools and Molecular Junctions Using Tailored $\operatorname{Re}_{6}$ Cluster Building Blocks
}

\begin{abstract}
At the occasion of the fiftieth birthday of the introduction of the term 'metal atom cluster' by F. A. Cotton in inorganic chemistry, it is the good time to make a review on the advances in the engineering of molecular assemblies and nanomaterials based on octahedral $\mathrm{Re}_{6}$ metal atom clusters. The latter exhibit unique intrinsic structural and physicochemical properties (orthogonal disposition of metallic sites that can be selectively functionalized, photoluminescence, redox, generation of singlet oxygen) that make them relevant building blocks for the structuration at the nanometric scale and functionalization of hybrid organic-inorganic materials and supramolecular frameworks. After synthesis by solid state chemistry techniques at high temperature, inorganic precursors built up on face-capped $\left[\left(\operatorname{Re}_{6} \mathrm{Y}_{8}{ }_{8}\right) \mathrm{Y}_{6}{ }_{6}\right]$ cluster units $(\mathrm{Y}=$ chalcogen and/or halogen) can be functionalized via solution chemistry techniques or organic melts to form $\left[\left(\operatorname{Re}_{6} \mathrm{Y}_{8}{ }_{8}\right) \mathrm{L}_{6}{ }_{6}\right](\mathrm{L}=\mathrm{CN}$, $\mathrm{OH}$, various organic ligands...). This work reports advances in the synthesis of $\left[\left(\operatorname{Re}_{6} \mathrm{Y}_{8}{ }^{\mathrm{i}}\right) \mathrm{Y}_{6}^{\mathrm{a}}{ }_{6}\right]$ and $\left[\left(\operatorname{Re}_{6} \mathrm{Y}_{8}{ }^{\mathrm{i}}\right) \mathrm{L}_{6}{ }_{6}\right]$ cluster units as well as on their use in the elaboration of supramolecular frameworks, nanoparticles, hybrid nanomaterials (co-polymers and liquid crystals) and active molecular junctions.
\end{abstract}

Keywords Rhenium metal atom clusters · Nanoparticles · Supramolecular frameworks · Copolymers and Liquid crystals · Functional surfaces

\section{Introduction.}

The solid state chemistry of metal atom clusters and in particular the solid state chemistry of octahedral metal atom clusters has been extensively studied since the 60's [1-8]. This chemistry has yielded a wide library of compounds with fascinating crystal structures and properties as superconductivity [9], thermoelectricity [10], intercalation/de-intercalation [11], Mott insulating behaviors [12] with potential applications, for instance, for energy conversion or the design of Random Access Memories (RAM). Besides their physical properties in the solid state, that originate from number of valence electrons per cluster available for metal-metal bonding and to the strength of electronic interactions between cluster units, many solid state compounds and in particular octahedral cluster compounds can be used as precursors to afford discrete soluble molecular species for the structuration and the design of molecular assemblies [13], extended molecular solids [14-25], supported materials and nanomaterials [21, 26, 27] that are of interest in the fields of hydrogen storage, sensors, imaging and displays.

Octahedral nanometer-sized metallic clusters of transition elements are associated with halogen or chalcogen ligands to form edge-bridged $\left[\left(\mathrm{M}_{6} \mathrm{~L}_{12}^{\mathrm{i}}\right) \mathrm{L}_{6}\right]^{\mathrm{a}-}$ and face-capped $\left.\left[\left(\mathrm{M}_{6} \mathrm{~L}_{8}{ }_{8}\right) \mathrm{L}_{6}\right]^{\mathrm{a}}\right]^{\mathrm{n}-}$ units $(\mathrm{a}=$ apical, $\mathrm{i}=$ inner). As sketched in Fig. 1, $\mathrm{M}_{6}$ clusters are bonded to six terminal ligands $\left(\mathrm{L}^{\mathrm{a}}\right)$ in both kinds of units but they are edge-bridged by twelve inner ligands in the $\left[\left(\mathrm{M}_{6} \mathrm{~L}_{12}^{\mathrm{i}}\right) \mathrm{L}_{6}^{\mathrm{a}}\right]^{\mathrm{n}-}$ unit $(\mathrm{M}=\mathrm{Nb}$ or Ta) and face-capped by eight inner ligands in the $\left[\left(\mathrm{M}_{6} \mathrm{~L}_{8}{ }^{\mathrm{i}}\right) \mathrm{L}_{6}^{\mathrm{a}}\right]^{\mathrm{n}-\mathrm{-}}$ unit $(\mathrm{M}=\mathrm{Mo}, \mathrm{W}$ or Re$)$. The intrinsic properties of $\mathrm{M}_{6}$ cluster units depend on both the nature of the metal, the number of valence electron and the nature of $\mathrm{L}^{\mathrm{i}}$ and $\mathrm{L}^{\mathrm{a}}$ ligands.

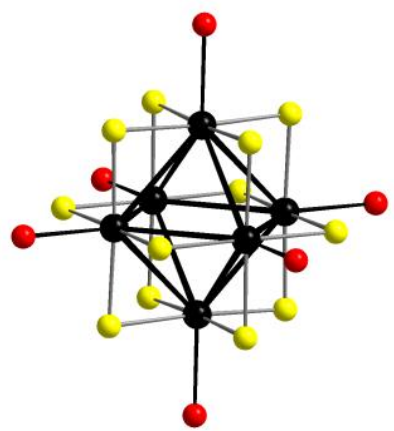

a)

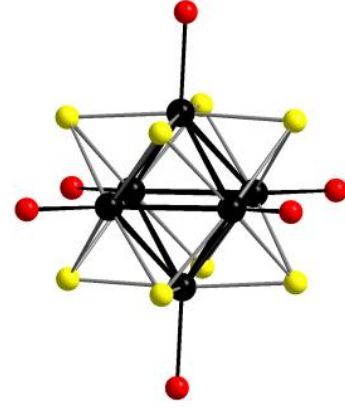

b)

Fig. 1 Representation of the edge-bridged $\left[\left(\mathrm{M}_{6} \mathrm{~L}^{\mathrm{i}}{ }_{12}\right) \mathrm{L}^{\mathrm{a}}\right]^{\mathrm{n}-}(\mathrm{a})$ and face-capped $\left[\left(\mathrm{M}_{6} \mathrm{~L}_{8}{ }^{\mathrm{i}}\right) \mathrm{L}_{6}\right]^{\mathrm{n}-}(\mathrm{b})$ units

Both $\left[\left(\mathrm{M}_{6} \mathrm{~L}_{12}^{\mathrm{i}}\right) \mathrm{L}_{6}^{\mathrm{a}}\right]^{\mathrm{n}-}$ and $\left[\left(\mathrm{M}_{6} \mathrm{~L}_{8}{ }^{\mathrm{i}}\right) \mathrm{L}_{6}^{\mathrm{a}}\right]^{\mathrm{n}-}$ exhibit a wide absorption window from $\mathrm{UV}$ to visible range [2838] but only the $\left[\left(\mathrm{M}_{6} \mathrm{~L}_{8}^{\mathrm{i}}\right) \mathrm{L}_{6}^{\mathrm{a}}\right]^{\mathrm{n}-}\left(\mathrm{M}=\mathrm{Re}, \mathrm{L}^{\mathrm{i}}=\mathrm{S}\right.$, Se or Te; $\mathrm{M}=\mathrm{Mo}$ or $\mathrm{W}, \mathrm{L}^{\mathrm{i}}=\mathrm{Cl}, \mathrm{Br}$ or $\left.\mathrm{I}\right)$ cluster units exhibit 
photoluminescence properties [35, 38-49]. Both units exhibit reversible electron-oxidation processes and magnetic properties when they carry unpaired valence electrons [30, 32, 35, 39, 50-62]. Compared with other metal-based solid state complexes, the added value of $\left[\left(\mathrm{M}_{6} \mathrm{~L}_{12}^{\mathrm{i}}\right) \mathrm{L}_{6}^{\mathrm{a}}\right]^{\mathrm{n}-}$ and $\left[\left(\mathrm{M}_{6} \mathrm{~L}_{8}{ }^{\mathrm{i}} \mathrm{L}_{6}{ }_{6}^{\mathrm{a}}\right]^{\mathrm{n}-}\right.$ is that the inorganic $\mathrm{L}^{\mathrm{a}}$ ligands can be exchanged by other $L^{\prime a}$ inorganic ones or functional organic ligands [29, 31, 63-68]. This substitution can be complete or partial leading to isomeric $\left[\left(\mathrm{M}_{6} \mathrm{~L}^{\mathrm{i}}{ }_{12}\right) \mathrm{L}_{\mathrm{x}}^{\mathrm{a}} \mathrm{L}^{{ }^{\prime}{ }_{6-\mathrm{a}}}\right]^{\mathrm{n}-/+}$ and $\left[\left(\mathrm{M}_{6} \mathrm{~L}_{8}{ }^{\mathrm{i}}\right) \mathrm{L}_{\mathrm{x}}^{\mathrm{a}} \mathrm{L}^{{ }^{\prime} \mathrm{a}}{ }_{6-\mathrm{x}}\right]^{\mathrm{n}-/+}$ cluster units. Interestingly, the $\left(\mathrm{M}_{6} \mathrm{~L}_{8}^{\mathrm{i}}\right)^{\mathrm{x}+}$ and $\left(\mathrm{M}_{6} \mathrm{~L}_{12}^{\mathrm{i}}\right)^{\mathrm{x}+}$ cores can be viewed as nodes that can be selectively functionalized for their controlled assembling by supramolecular interactions via linker in one, two or three crystallographic directions in extended molecular solid. $\left[\left(\mathrm{M}_{6} \mathrm{X}_{12}^{\mathrm{i}}\right) \mathrm{L}_{6}{ }_{6}\right]^{\mathrm{n}-}$ cluster units $\left(\mathrm{X}=\right.$ halogen and $\mathrm{L}=\mathrm{H}_{2} \mathrm{O}$, $\mathrm{N}_{3}^{-}, \mathrm{CN}^{-}$and $\mathrm{SCN}^{-}$groups) [69-72] have been involved in the design of extended frameworks [73, 74], deposited as redox-active moieties on gold electrodes [75] or used, in the case of tantalum, for the structural determination of proteins $[76,77]$. It is worth noting that the chemistry of $\left[\left(\mathrm{M}_{6} \mathrm{~L}_{8}^{\mathrm{i}}\right) \mathrm{L}_{6}^{\mathrm{a}}\right]^{\mathrm{n}-}$ face-capped units is much more developed than that of $\left[\left(\mathrm{M}_{6} \mathrm{X}_{12}{ }_{12}\right) \mathrm{L}_{6}^{\mathrm{a}}\right]^{\mathrm{n}-}$ edge-bridged ones owing to, probably, a higher chemical stability with higher oxidation potential compared to $\left[\left(\mathrm{M}_{6} \mathrm{X}_{12}^{\mathrm{i}}\right) \mathrm{L}_{6}^{\mathrm{a}}\right]^{\mathrm{n}-}$ cluster units but also because such units exhibit additional unique photoluminescence properties, photocatalytic activity [78, 79] and capability to generate singlet oxygen [62, 80, 81]. Many recent works have been reported on the elaboration and design of $\mathrm{Mo}_{6}$ cluster-based molecular assemblies, nanomaterials and functional surfaces [13, 20, 21, 27, 82-84]. This review focuses on the recent advances and perspectives on molecular assemblies, nanomaterials and surfaces using rhenium cluster building blocks which is actually a hot topic of research. The idea to prepare solid state compounds and to use them as precursors in the elaboration of nanomaterials is not straightforward and can be decomposed in three important chronologic steps. The first step started with the pioneering work of P. Batail and A. Perrin with the discovery of the solubility of $\mathrm{K}\left[\left(\mathrm{Re}_{6} \mathrm{Se}_{5}{ }_{5} \mathrm{Cl}_{3}{ }_{3}\right) \mathrm{Cl}_{6}^{\mathrm{a}}\right.$ ] in ethanol [85]. This property of $\mathrm{Re}_{6}$ clusters was subsequently used for the design of charge transfer salts. Then, the second step started with the works of R. H. Holm, J. R. Long, V. E. Fedorov and Y. Sasaki consisting in the functionalization of the $\mathrm{Re}_{6}$ clusters by donor ligands like $\mathrm{CN}$, phosphine or pyridine derivatives. Indeed, a multiplicity of molecular assemblies and extended supramolecular solids or extended frameworks were synthesized and characterized. The third step started at the beginning of 2000s by the engineering of hybrid molecular compounds and nanomaterials [66, 86-92] using the $\operatorname{Re}_{6}$ clusters as building blocks or active moieties for applications ranging from biomedicine and bio-imaging to lighting and displays. This field of research is becoming more and more interdisciplinary from the synthesis of solid state compounds, functionalization of clusters, design of multifunctional materials and evaluation of toxicity. Fifty years after the introduction by F. A. Cotton of the term metal atom cluster, this review reports advances of this interdisciplinary work consisting to use $\mathrm{Re}_{6}$ cluster-based solid state compounds for the engineering of near infrared emitting liquid crystals and copolymers, extended porous frameworks, theranostic tools and molecular junctions. This constitutes a first step before applications in many fields ranging from telecoms, molecular electronics, displays, lighting and medicine.

\section{Art of work: from solid state compounds to functional molecular assemblies}

The solid state synthesis and excision reactions to form soluble scaffolds for functional molecular assemblies have been largely described earlier [36, 93-96], in the following main results are summarized (Table 1). The synthesis methods of the cluster compounds may be divided into two main groups: the high-temperature synthesis, which is carried out in closed systems (usually, in sealed evacuated tubes), and the synthesis in solution.

\section{II.a. Synthesis of cluster precursors by high temperature and solution routes}

The high-temperature reactions are extremely important for the synthesis of the $\left(\operatorname{Re}_{6} \mathrm{Q}_{8}\right)^{\mathrm{n}+}$ cluster cores which hitherto have never been obtained in solution. In the solid state, the cluster core is stabilized by halogen and/or chalcogen to form polymeric frameworks as for instance $\operatorname{Re}_{6} \mathrm{Q}_{8} \mathrm{Br}_{2}(\mathrm{Q}=\mathrm{S}, \mathrm{Se})$ or $\operatorname{Re}_{6} \mathrm{Te}_{15}$. When alkali metal salts are added to the starting mixture, the cluster core is stabilized by halogen to form discrete charged units as found for instance in the double salts $\mathrm{Cs}_{4}\left[\left(\operatorname{Re}_{6} \mathrm{Q}_{8}{ }_{8}\right) \mathrm{X}_{6}{ }_{6}\right] \mathrm{CsX}(\mathrm{Q}=\mathrm{S}, \mathrm{Se} ; \mathrm{X}=\mathrm{Br}$, I). The preparation method for $\mathrm{Re}_{6}$ cluster-based compounds is based on the assumption that a phase thermodynamically stable under defined experimental conditions (i.e. temperature, pressure) is obtained from starting precursors taken in the appropriate ratio. Simple substances and binary compounds (for example, metal halides, metal chalcogenides, chalcogenides and halides) are used as starting compounds. For instance, polymeric $\operatorname{Re}_{6} \mathrm{Q}_{8} \mathrm{Br}_{2}$ is prepared from elements, addition of excess of $\mathrm{CsX}$ loading results in formation of $\mathrm{Cs}_{4}\left[\left(\operatorname{Re}_{6} \mathrm{Q}_{8}{ }^{i}\right) \mathrm{X}_{6}^{\mathrm{a}}\right] \mathrm{CsX}$ with discrete clusters. In addition to the ratio of the starting compounds in the reaction mixture, the synthesis temperature is the key point of the procedure. The standard procedure for the synthesis of a cluster chalcohalogenide can be described as follows. 
First, a quartz tube is loaded with starting compounds and then evacuated and sealed. If necessary, the tube is cooled down by liquid nitrogen prior to evacuation in order to avoid the loss of volatile components $\left(\mathrm{e} . \mathrm{g}\right.$. $\mathrm{Br}_{2}$ or $\mathrm{I}_{2}$ ). Afterwards, the sealed tube is placed into a furnace and heated at temperature ranging from $500^{\circ} \mathrm{C}$ to $900^{\circ} \mathrm{C}$ depending on the chemical system. The reaction time varies from several tens of hours up to several days, in order to complete the reaction. Such high temperature reactions produce exclusively valence electron-precise counts irrespectively to stoichiometry or reaction conditions. The most widely used starting precursors are $\operatorname{Re}_{6} \mathrm{Q}_{8} \mathrm{Br}_{2}(\mathrm{Q}=\mathrm{S}, \mathrm{Se}), \operatorname{Re}_{6} \mathrm{Te}_{15}, \mathrm{Cs}_{4}\left[\left(\operatorname{Re}_{6} \mathrm{Q}_{8}{ }_{8}\right) \mathrm{X}_{6}^{\mathrm{a}}\right] \mathrm{CsX}(\mathrm{Q}=\mathrm{S}, \mathrm{Se} ; \mathrm{X}=\mathrm{Br}, \mathrm{I})$. The subsequent reaction of $\mathrm{Re}_{6} \mathrm{Q}_{8} \mathrm{Br}_{2}$ and $\mathrm{Re}_{6} \mathrm{Te}_{15}$ with $\mathrm{KCN}, \mathrm{KOH}$ or KNCS yields hexasubstituted units with the $\left[\left(\operatorname{Re}_{6} \mathrm{Q}_{8}{ }_{8}\right) \mathrm{L}_{6}\right]^{4-}$ formula ( $\mathrm{L}=\mathrm{CN}$, OH or NCS). Let us note that the reaction of $\mathrm{Re}_{6} \mathrm{Se}_{8} \mathrm{Br}_{2}$ with molten $\mathrm{KOH}$ at $280{ }^{\circ} \mathrm{C}$ results in the formation of a $\left(\mathrm{Re}_{6} \mathrm{Se}_{4}{ }_{4} \mathrm{O}_{4}{ }^{\mathrm{i}}\right)^{2+}$ cluster core with ordered ligands. Four positions of one face of the $\mathrm{Se}_{4} \mathrm{O}_{4}$ cube inscribing the $\mathrm{Re}_{6}$ cluster are occupied exclusively by $\mathrm{Se}$ atoms and the four $\mathrm{O}$ atoms lie in the opposite face [97]. Cyanocomplexes are formed by reactions of $\mathrm{ReS}_{2}$ (or $\mathrm{ReSe}_{2}$ ) with $\mathrm{KCN}$ leading to the formation of two unusual chalcocyanide compounds, $\mathrm{K}_{4}\left[\left(\operatorname{Re}_{6} \mathrm{~S}_{8}{ }_{8}\right) \mathrm{S}^{\mathrm{a}-\mathrm{a}}{ }_{4 / 2}(\mathrm{CN})^{\mathrm{a}}{ }_{2}\right]$ and $\mathrm{K}_{4}\left[\left(\operatorname{Re}_{6} \mathrm{~S}_{8}{ }_{8}\right)\left(\mathrm{Se}_{2}\right)^{\mathrm{a}-\mathrm{a}}{ }_{2 / 2}(\mathrm{CN})_{4}^{\mathrm{a}}\right]$, that contain bridging ligands $\mathrm{S}^{2-}$ and $\left(\mathrm{Se}_{2}\right)^{2-}$ together with terminal $\mathrm{CN}^{-}$ligands [98]. A chain polymer $\mathrm{Cs}_{4}\left[\left(\operatorname{Re}_{6} \mathrm{~S}_{8}{ }^{\mathrm{i}}\right) \mathrm{S}^{\mathrm{a}-}\right.$ $\left.\mathrm{a}_{2 / 2}(\mathrm{CN})^{\mathrm{a}}{ }_{4}\right]$ which is the next member of a series $\mathrm{M}_{4}\left[\left(\operatorname{Re}_{6} \mathrm{~S}_{8}\right) \mathrm{S}^{\mathrm{a}-\mathrm{a}}(6-2 \mathrm{x}) / 2(\mathrm{CN})^{\mathrm{a}}{ }_{2 \mathrm{x}}\right]$, where $\mathrm{M}$ is an alkali metal, was obtained with high yield by high temperature reaction of $\mathrm{ReS}_{2}$ with $\mathrm{KCN}$ in presence of $\mathrm{CsCl}$ excess [99]. Four mixed ligand octahedral cluster complexes $\mathrm{K}\left[\left(\mathrm{Re}_{6} \mathrm{~S}_{8}{ }^{\mathrm{i}}\right) \mathrm{F}_{3}{ }_{3}\left(\mathrm{H}_{2} \mathrm{O}\right)_{3}{ }_{3}\right] \cdot 7 \mathrm{H}_{2} \mathrm{O}, \mathrm{H}_{3} \mathrm{O}\left[\left(\operatorname{Re}_{6} \mathrm{Se}_{8}{ }^{\mathrm{i}}\right) \mathrm{F}_{3}{ }_{3}\left(\mathrm{H}_{2} \mathrm{O}\right)_{3}^{\mathrm{a}}\right] \cdot 7 \mathrm{H}_{2} \mathrm{O}$ and $\left[\left(\mathrm{Re}_{6} \mathrm{Q}_{8}{ }^{\mathrm{i}}\right) \mathrm{F}_{2}{ }_{2}\left(\mathrm{H}_{2} \mathrm{O}\right)^{\mathrm{a}}{ }_{4}\right] \cdot 12 \mathrm{H}_{2} \mathrm{O}(\mathrm{Q}=\mathrm{S}$ or Se$)$, have been synthesized using the reaction of corresponding rhenium chalcobromide complexes $\mathrm{K}_{4}\left[\left(\operatorname{Re}_{6} \mathrm{~S}_{8}{ }_{8}\right) \mathrm{Br}_{6}{ }_{6}\right] \cdot 2 \mathrm{H}_{2} \mathrm{O}$ and $\mathrm{Cs}_{3}\left[\left(\operatorname{Re}_{6} \mathrm{Se}_{8}{ }^{\mathrm{i}}\right) \mathrm{Br}_{6}^{\mathrm{a}}\right] \cdot \mathrm{H}_{2} \mathrm{O}$ with molten $\mathrm{KHF}_{2}$ and further crystallization form aqueous solutions under different conditions [100].

\section{II.b. Solution chemistry}

The solubility of $\left[\left(\operatorname{Re}_{6} \mathrm{Q}_{8}{ }_{8}\right) \mathrm{X}_{6}\right]^{\mathrm{n}-}$ cluster units is governed by the charge of the units and the nature of counter cations. $\left[\left(\operatorname{Re}_{6} \mathrm{Q}_{8}{ }^{\mathrm{i}}\right) \mathrm{X}_{6}^{\mathrm{a}}\right]^{\mathrm{n}-}(\mathrm{X}=$ halogen $)$ cluster units associated with alkaline earth ions are soluble in alcohol and/or in water. The functionalization by organic moieties requires the solubilization of $\operatorname{Re}_{6}$ clusters in organic media. Indeed, after dissolution of inorganic precursors in aqueous solutions, the precipitation of $\left[\left(\operatorname{Re}_{6} \mathrm{Q}_{8}{ }_{8}\right) \mathrm{X}_{6}^{\mathrm{a}}\right]^{\mathrm{n}-}$ units with tetrabutylammonium $\left(\left(n-\mathrm{C}_{4} \mathrm{H}_{9}\right)_{4} \mathrm{~N}\right)^{+}$organic cations affords $\left(\left(n-\mathrm{C}_{4} \mathrm{H}_{9}\right)_{4} \mathrm{~N}\right)_{n}\left[\left(\mathrm{Re}_{6} \mathrm{Q}_{8}\right)^{\mathrm{i}_{1}} \mathrm{X}_{6}^{\mathrm{a}}\right](n=4$ for $\mathrm{S}, n$ $=3$ for $\mathrm{Se})$ precursors, from which a wide variety of hybrid $\left[\left(\operatorname{Re}_{6} \mathrm{Q}_{8}{ }^{\mathrm{i}}\right) \mathrm{L}_{6}^{\mathrm{a}}\right]^{2+}$ units based on a $\left(\operatorname{Re}_{6} \mathrm{Q}_{8}\right)^{2+}$ inorganic cluster core and functional organic moieties utilized as apical ligands can be prepared $(\mathrm{L}=\mathrm{N}$ - and $\mathrm{P}$-donor ligands). Indeed, the more straightforward functionalization method is the direct reaction of $(\mathrm{TBA})_{3}\left[\left(\operatorname{Re}_{6} \mathrm{Q}_{8}{ }_{8}\right) \mathrm{Cl}_{6}^{\mathrm{a}}{ }_{6}\right](\mathrm{TBA}=$ tetrabutyl ammonium) with pyridine and functional pyridine to form bi- and trifunctional species $[37,101]$. It has even been demonstrated that monofunctional $\left[\left(\operatorname{Re}_{6} \mathrm{Q}_{8}{ }_{8}\right)\left(\mathrm{Cl}_{5}{ }_{5}(4-\right.\right.$ phenylpyridine $\left.)^{\mathrm{a}}\right]^{3-}$ species is obtained by reaction between $(\mathrm{TBA})_{4}\left[\left(\mathrm{Re}_{6} \mathrm{Q}_{8}{ }_{8}\right) \mathrm{Cl}_{6}^{\mathrm{a}}\right]$ and 4-phenyl-pyridine in a $\mathrm{MeCN}$ forced by photoirradiation of the solution [102]. In order to obtain higher substituted cluster units, the use of phosphine derivatives is preferred. Usually reactions with phosphine are more complete [66, 86, 87, 94, 103], hexasubstituted $\left[\left(\operatorname{Re}_{6} Q_{8}{ }_{8}\right) L_{6}^{a}\right]^{2+}$ functional units were prepared from $\left[\left(\operatorname{Re}_{6} Q_{8}{ }^{i}\right) I_{6}{ }_{6}\right]^{3-}$ units $(Q=S$, Se $)$ after the prior removal of iodine apical ligands from the cluster core by reaction with silver salt in order to facilitate the apical ligand substitution. Partially substituted $\left[\left(\operatorname{Re}_{6} \mathrm{Q}_{8}{ }_{8}\right)\left(\mathrm{PEt}_{3}\right)^{\mathrm{a}}{ }_{6-x} \mathrm{I}_{x}{ }_{x}\right]^{(2-x)+}$ units were synthesized by the direct reaction of $\left[\left(\operatorname{Re}_{6} Q^{\mathrm{i}}\right) \mathbf{I}_{6}\right]^{3-}$ units with $\mathrm{PEt}_{3}$, leading to a set of $\left.\left[\left(\operatorname{Re}_{6} \mathrm{Q}_{8}{ }^{\mathrm{i}}\right)\left(\mathrm{PEt}_{3}\right)_{6-x}{ }_{6}\right) \mathbf{I}_{x}\right]^{(2-x)+}$ anionic units with different $x$ values and possible isomeric units. The Re-P bonds being very strong, functional $\left[\left(\operatorname{Re}_{6} \mathrm{Q}_{8}{ }_{8}\right)\left(\mathrm{PEt}_{3}\right)^{\mathrm{a}}{ }_{6-}\right.$ $\left.\left.{ }_{x}\right) \mathrm{L}_{x}^{\mathrm{a}}\right]^{2+}$ units were obtained by reactions of $\left[\left(\operatorname{Re}_{6} \mathrm{Q}_{8}{ }_{8}\right)\left(\mathrm{PEt}_{3}\right)_{6-x}^{\mathrm{a}} \mathrm{I}_{x}\right]^{(2-x)+}$ with various $\mathrm{L}$ in the presence of $\mathrm{Ag}^{+}$in order to remove the apical iodine atoms without destroying the $\mathrm{Re}-\mathrm{PPh}_{3}$ bond. Beyond different types of functional $\operatorname{Re}_{6}$ supramolecular units, this technique afforded original supramolecular network based on hydrogen-bonding by grafting, for instance, isonicotinamide on the cluster. It turns out that the lower reactivity of the $\left(\operatorname{Re}_{6} S_{8}\right)^{2+/ 3+}$ cluster cores compared to that of $\left(\operatorname{Re}_{6} \operatorname{Se}_{8}{ }^{i}\right)^{2+/ 3+}$ leads to a smaller set of supramolecular assemblies with sulfur than with selenium. All these derivatives have been widely studied experimentally and theoretically for their spectroscopic and photophysical properties [38-42, 104-108].

\section{II.c. Mixing Solid state and solution chemistries, design of functional $\mathrm{Re}_{6}$ cluster units containing $\mathrm{CN}$ and OH apical ligands: $\left[\left(\operatorname{Re}_{6} Q^{i}{ }_{8}\right)(O H)^{a}{ }_{6-x}(C N)^{a}{ }_{x}\right]^{4-}$}

In a similar way to what has been observed with $\mathrm{Re}-\mathrm{P}$ bonds for phosphine ligands, the $\mathrm{Re}-\mathrm{CN}$ bond is very stable at room temperature. $\left[\left(\operatorname{Re}_{6} \mathrm{Q}_{8}^{\mathrm{i}}\right) \mathrm{L}_{6}^{\mathrm{a}}\right]^{\mathrm{n}-}\left(\mathrm{L}=\mathrm{CN}^{-}, \mathrm{OH}^{-}, \mathrm{NCS}^{-}, \mathrm{N}_{3}^{-}\right)$cluster units associated with alkaline earth ions are readily soluble in water [48, 49, 109-120]. Thanks to the bidentate nature of $\mathrm{CN}^{-}$group, the $\left[\left(\operatorname{Re}_{6} \mathrm{Q}_{8}^{\mathrm{i}}\right)(\mathrm{CN})_{6}^{\mathrm{a}}\right]^{\mathrm{n}-}(\mathrm{Q}=\mathrm{S}, \mathrm{Se}, \mathrm{Te})$ cluster units have been widely used for the elaboration of low dimensional cluster framework by co-crystallization via $\mathrm{CN}$ with transition metal cations. The hydroxo species are interesting 
since the $\mathrm{OH}$ groups react with acid to form water molecules $[49,117]$. They also react with carboxylic acids to form corresponding carboxylate cluster complexes [41, 42, 88, 121]. Indeed, based on the fact that the $\left[\left(\operatorname{Re}_{6} \mathrm{Q}_{8}{ }_{8}\right)(\mathrm{CN})_{6}^{\mathrm{a}}\right]^{4-}$ cluster unit is chemically inert and that $\left[\left(\mathrm{Re}_{6} \mathrm{Q}_{8}{ }_{8}\right)(\mathrm{OH})_{6}^{\mathrm{a}}\right]^{4-}$ contains six OH groups capable to react with an acid, the possibility to block apical sites with $\mathrm{CN}$ groups will enable to tailor building blocks with controlled number and positions of reactive $\mathrm{OH}$ sites. As stressed above, the solid state reaction of $\operatorname{Re}_{6} \mathrm{Q}_{8} \mathrm{Br}_{2}$ with $\mathrm{KCN}$ or $\mathrm{KOH}[110,115,122]$ affords hexasubstituted units with the $\left[\left(\operatorname{Re}_{6} \mathrm{Q}_{8}{ }_{8}\right) \mathrm{L}_{6}^{\mathrm{a}}\right]^{4-}$ formula and solid state reaction of $\left[\left(\operatorname{Re}_{6} \mathrm{~S}_{8}{ }_{8}\right)(\mathrm{CN})_{4} \mathrm{~S}^{\mathrm{a}-\mathrm{a}}{ }_{2 / 2}\right]^{4-}$ with $\mathrm{KOH}$ affords trans-[( $\left.\left.\mathrm{Re}_{6} \mathrm{~S}_{8}{ }^{\mathrm{i}}\right)(\mathrm{CN})_{4}^{\mathrm{a}}(\mathrm{OH})_{2}^{\mathrm{a}}\right]^{4-}$ anionic cluster unit [118]. Protonation of $\left[\left(\operatorname{Re}_{6} \mathrm{Q}_{8}{ }_{8}\right)(\mathrm{OH})_{6}^{\mathrm{a}}\right]^{4-}$ cluster units leads to the formation of $\left[\left(\operatorname{Re}_{6} \mathrm{Q}_{8}{ }_{8}\right)\left(\mathrm{H}_{2} \mathrm{O}\right)^{\mathrm{a}}{ }_{2}(\mathrm{OH})^{\mathrm{a}}{ }_{4}\right]^{2-}$ and $\left[\left(\mathrm{Re}_{6} \mathrm{Q}_{8}{ }_{8}\right)\left(\mathrm{H}_{2} \mathrm{O}\right)_{4}^{\mathrm{a}}(\mathrm{OH})_{2}^{\mathrm{a}}\right]^{0}$ species with low solubility owing to strong hydrogen bonding between clusters [117]. It is worth noting that compounds based on $\left[\left(\operatorname{Re}_{6} \mathrm{Q}_{8}^{\mathrm{i}}\right)\left(\mathrm{H}_{2} \mathrm{O}\right)^{\mathrm{a}}{ }_{2}(\mathrm{OH})_{4}^{\mathrm{a}}\right]^{2-}$ units like $\mathrm{K}_{2}\left[\left(\mathrm{Re}_{6} \mathrm{~S}_{8}{ }_{8}\right)\left(\mathrm{H}_{2} \mathrm{O}\right)^{\mathrm{a}}{ }_{2}(\mathrm{OH})_{4}^{\mathrm{a}}{ }_{4}{ }_{2} \mathrm{H}_{2} \mathrm{O}\right.$ exhibit extended 3D hydrogen-bonding networks [117]. Protonation of the $\left[\left(\operatorname{Re}_{6} \mathrm{~S}_{8}{ }_{8}\right)(\mathrm{CN})_{6}^{\mathrm{a}}\right]^{4-}$ cluster complex was not observed under similar experimental conditions up to $\mathrm{pH} 1$. On the other hand, the $\mathrm{K}_{4}\left[\left(\mathrm{Re}_{6} \mathrm{~S}_{8}{ }_{8}\right)(\mathrm{CN})^{\mathrm{a}}{ }_{4}(\mathrm{OH})^{\mathrm{a}}{ }_{2}\right]$ is very soluble in water at $\mathrm{pH}>10.5$, a $\mathrm{pH}$ increase in range $5.5<\mathrm{pH}<9$ enables the formation of $\left[\left(\mathrm{Re}_{6} \mathrm{~S}_{8}{ }_{8}\right)(\mathrm{CN})_{4}^{\mathrm{a}}(\mathrm{OH})^{\mathrm{a}}\left(\mathrm{H}_{2} \mathrm{O}\right)\right]^{3-}$ and finally $\left[\left(\mathrm{Re}_{6} \mathrm{~S}_{8}{ }_{8}\right)(\mathrm{CN})^{\mathrm{a}}{ }_{4}\left(\mathrm{H}_{2} \mathrm{O}\right)^{\mathrm{a}}{ }_{2}\right]^{2-}$ at $\mathrm{pH}<3.5$ [49]. The latter constitute thus useful building blocks for the elaboration of monofunctional and trans-bifunctional molecular assemblies by reaction with functional acids in aqueous solutions. A relevant strategy has been developed to obtain organic solvent soluble $\left[\left(\operatorname{Re}_{6} \mathrm{Q}_{8}{ }_{8}\right) \mathrm{L}_{6}^{\mathrm{a}}\right]$ clusters in high yield without the use of tetrabutyl ammonium salts as developed in the case of rhenium chalcohalogenides. It consists in the reaction between $\left[\left(\operatorname{Re}_{6} \mathrm{Q}_{8}^{\mathrm{i}}\right)(\mathrm{OH})_{6}^{\mathrm{a}}\right]^{4-}$ with an excess of tert-butylpyridine (tbp) in water leading to the precipitation of the neutral $\left[\left(\operatorname{Re}_{6} \mathrm{Q}_{8}{ }_{8}\right)(\mathrm{tbp})_{4}^{\mathrm{a}}(\mathrm{OH})_{2}{ }_{2}\right]^{0}$ cluster units. It turns out that $\left[\left(\operatorname{Re}_{6} \mathrm{Q}_{8}{ }_{8}\right)(\mathrm{tbp})^{\mathrm{a}}{ }_{4}(\mathrm{OH})^{\mathrm{a}}{ }_{2}\right]^{0}$ is soluble in organic solvents and that the trans-isomer can be separated from the cis-isomer by two successive recrystallizations in $\mathrm{CH}_{2} \mathrm{Cl}_{2}$-ether mixtures [41]. The added value of all these species is that they are not air sensitive and that they can be produced in a large scale. 
Table 1 Synthetic approaches to the common $\left(\operatorname{Re}_{6} \mathrm{Q}_{8}\right)^{2+}$-cluster-core-based precursors used for preparation of cluster containing functional materials and hybrid materials

\begin{tabular}{|c|c|c|c|}
\hline Complex & Starting materials & Reaction conditions & Reference \\
\hline$\left[\left(\mathrm{Re}_{6} \mathrm{~S}_{8}\right) \mathrm{Cl}_{6}\right]^{4-}$ & $\begin{array}{l}\text { 1) } \mathrm{Re}, \mathrm{S}, \mathrm{ReCl}_{5} \text { and } \mathrm{MCl} \\
(\mathrm{M}=\mathrm{Tl} \text { or } \mathrm{Cs}) \\
\text { 2) } \mathrm{Re}, \mathrm{S}, \mathrm{S}_{2} \mathrm{Cl}_{2} \text { and } \mathrm{KCl}\end{array}$ & $\begin{array}{l}\text { 1) } 900{ }^{\circ} \mathrm{C}, \sim 116 \mathrm{~h} \\
\text { 2) } 8500^{\circ} \mathrm{C}, 7 \text { days }\end{array}$ & {$[123,124]$} \\
\hline $\begin{array}{l}{\left[\left(\operatorname{Re}_{6} \mathrm{Q}_{8}\right) \mathrm{X}_{6}\right]^{4-}} \\
(\mathrm{Q}=\mathrm{S}, \mathrm{X}=\mathrm{Br} \text { or } \mathrm{I} \\
\mathrm{Q}=\mathrm{Se}, \mathrm{X}=\mathrm{I})\end{array}$ & $\operatorname{Re}, \mathrm{Q}, \mathrm{X}_{2}$ and $\mathrm{CsX}$ & $850{ }^{\circ} \mathrm{C}, 100 \mathrm{~h}$ & {$[36,125]$} \\
\hline $\begin{array}{l}{\left[\left(\operatorname{Re}_{6} \mathrm{Q}_{8}\right) \mathrm{X}_{6}\right]^{4-}} \\
(\mathrm{Q}=\mathrm{S}, \mathrm{X}=\mathrm{Br} \\
\mathrm{Q}=\mathrm{Se}, \mathrm{X}=\mathrm{Cl})\end{array}$ & {$\left[\left(\operatorname{Re}_{6} \mathrm{Q}_{8}\right)(\mathrm{OH})_{6}\right]^{4-}, \mathrm{CsX}$ and $\mathrm{HX}$} & Boiling an aqueous solution, $10 \mathrm{~min}$ & [115] \\
\hline $\begin{array}{l}{\left[\left(\operatorname{Re}_{6} \mathrm{Q}_{8}\right) \mathrm{X}_{6}\right]^{3-}} \\
(\mathrm{Q}=\mathrm{S}, \mathrm{X}=\mathrm{Cl}, \mathrm{Br} \text { or } \mathrm{I} \\
\mathrm{Q}=\mathrm{Se}, \mathrm{X}=\mathrm{I})\end{array}$ & {$\left[\left(\operatorname{Re}_{6} \mathrm{Q}_{8}\right) \mathrm{X}_{6}\right]^{4-}$} & $\begin{array}{l}\text { oxidation of }\left[\left(\mathrm{Re}_{6} \mathrm{Q}_{8} \mathrm{X}_{6}\right]^{4-} \text { by } \mathrm{SOCl}_{2}, \mathrm{SOBr}_{2}\right. \\
\text { or } \mathrm{H}_{2} \mathrm{SO}_{4} \text { in an acetonitrile or a } \mathrm{CH}_{2} \mathrm{Cl}_{2} \\
\text { solution }\end{array}$ & {$[36,55]$} \\
\hline $\begin{array}{l}{\left[\left(\mathrm{Re}_{6} \mathrm{Q}_{8}\right)(\mathrm{CN})_{6}\right]^{4-}} \\
(\mathrm{Q}=\mathrm{S} \text { or } \mathrm{Se})\end{array}$ & $\begin{array}{l}\text { cesium salt of }\left[\left(\operatorname{Re}_{6} \mathrm{~S}_{8}\right) \mathrm{Br}_{6}\right]^{4-} \text { or } \\
{\left[\left(\operatorname{Re}_{6} \mathrm{Se}_{8}\right) \mathrm{I}_{6}\right]^{4-} \text { and } \mathrm{NaCN}}\end{array}$ & $635^{\circ} \mathrm{C}, 25 \mathrm{~h}$ & [111] \\
\hline$\left[\left(\operatorname{Re}_{6} \mathrm{~S}_{8}\right)(\mathrm{CN})_{6}\right]^{4-}$ & $\mathrm{Re}_{6} \mathrm{Te}_{15}$ and $\mathrm{KSCN}$ & $500^{\circ} \mathrm{C}, 24 \mathrm{~h}$ & [109] \\
\hline $\begin{array}{l}{\left[\left(\operatorname{Re}_{6} \mathrm{Q}_{8}\right)(\mathrm{CN})_{6}\right]^{4-}} \\
(\mathrm{Q}=\mathrm{S}, \mathrm{Se} \text { or } \mathrm{Te})\end{array}$ & $\begin{array}{l}\operatorname{Re}_{6} \mathrm{~S}_{8} \mathrm{Br}_{2}, \mathrm{Re}_{6} \mathrm{Se}_{8} \mathrm{Br}_{2} \text { or } \mathrm{Re}_{6} \mathrm{Te}_{15} \\
\text { and } \mathrm{KCN}\end{array}$ & $600{ }^{\circ} \mathrm{C}, 48 \mathrm{~h}$ & $\begin{array}{l}{[110,112,} \\
122]\end{array}$ \\
\hline $\begin{array}{l}{\left[\left(\mathrm{Re}_{6} \mathrm{Q}_{8}\right)(\mathrm{CN})_{6}\right]^{4-}} \\
(\mathrm{Q}=\mathrm{Se} \text { or } \mathrm{Te})\end{array}$ & $\begin{array}{l}\text { 1) } \operatorname{Re}_{6} \mathrm{Te}_{15}, \mathrm{Se} \text { and } \mathrm{NaCN} \\
\text { 2) } \mathrm{Re}_{6} \mathrm{Te}_{15} \text { and } \mathrm{NaCN}\end{array}$ & $600^{\circ} \mathrm{C}, 24 \mathrm{~h}$ & [93] \\
\hline $\begin{array}{l}{\left[\left(\mathrm{Re}_{6} \mathrm{Q}_{8}\right)(\mathrm{NCS})_{6}\right]^{4-}} \\
(\mathrm{Q}=\mathrm{S} \text { or } \mathrm{Se})\end{array}$ & $\begin{array}{l}\text { 1) }[\mathrm{TBA}]_{3}\left[\left(\mathrm{Re}_{6} \mathrm{~S}_{8}\right) \mathrm{Cl}_{6}\right] \text { and } \\
\mathrm{KSCN} \\
\text { 2) }\left[\left(\mathrm{Re}_{6} \mathrm{Se}_{8}\right)\left(\mathrm{MeCN}_{6}\right]^{2+} \text { and }\right. \\
\mathrm{SCN} \\
\text { 3) } \mathrm{Cs}_{2}\left[\left(\mathrm{Re}_{6} \mathrm{Se}_{8}\right) \mathrm{Br}_{4}\right] \text { and } \mathrm{KSCN}\end{array}$ & $\begin{array}{l}\text { 1) } 200{ }^{\circ} \mathrm{C}, 1 \mathrm{~h} \\
\text { 2) reflux of a chlorobenzene-DMF }(2: 1 \mathrm{v} / \mathrm{v}) \\
\text { solution under Ar, } 12 \mathrm{~h} \\
\text { 3) reaction in a mechanochemical reactor at } \\
\text { room temperature, } 20 \mathrm{~h}\end{array}$ & [113] \\
\hline $\begin{array}{l}{\left[\left(\mathrm{Re}_{6} \mathrm{~S}_{8}\right)\left(\mathrm{PEt}_{3}\right)_{x} \mathrm{X}_{6-x}\right]^{x-4}} \\
(\mathrm{X}=\mathrm{Cl} \text { or } \mathrm{Br})\end{array}$ & $\begin{array}{l}{\left[\left(\mathrm{Re}_{6} \mathrm{~S}_{8}\right) \mathrm{Cl}_{6}\right]^{4-} \text { or }\left[\left(\mathrm{Re}_{6} \mathrm{~S}_{8}\right) \mathrm{Br}_{6}\right]^{3-}} \\
\text { and } \mathrm{PEt}_{3}\end{array}$ & reflux of a DMF solution under $\mathrm{N}_{2}$ & {$[86,94]$} \\
\hline$\left[\left(\operatorname{Re}_{6} \mathrm{Se}_{8}\right)\left(\mathrm{PEt}_{3}\right)_{x} \mathrm{I}_{6-x}\right]^{x-4}$ & {$\left[\left(\operatorname{Re}_{6} \mathrm{Se}_{8}\right) \mathrm{I}_{6}\right]^{3-}$ and $\mathrm{PEt}_{3}$} & $\begin{array}{l}\text { reflux of an acetonitrile or a DMF solution } \\
\text { under } \mathrm{N}_{2}\end{array}$ & [103] \\
\hline $\begin{array}{l}{\left[\left(\operatorname{Re}_{6} \mathrm{Se}_{8}\right)\left(\mathrm{PEt}_{3}\right)_{6-}\right.} \\
\left.x(\mathrm{~L})_{x}\right]^{2+} \\
(\mathrm{X}=\mathrm{MeCN}, \mathrm{DMF}, \\
\text { DMSO or pyridine })\end{array}$ & {$\left[\left(\mathrm{Re}_{6} \mathrm{Se}_{8}\right)\left(\mathrm{PEt}_{3}\right)_{x} \mathrm{I}_{6-x}\right]^{x-4}$ and $\mathrm{Ag}^{+}$} & $\begin{array}{l}\text { reaction in a mixture of } \mathrm{CH}_{2} \mathrm{Cl}_{2} \text { with } \mathrm{MeCN} \text {, } \\
\text { DMF, DMSO or pyridine, respectively, at } \\
\text { room temperature }\end{array}$ & $\begin{array}{l}{[96,103,} \\
126]\end{array}$ \\
\hline $\begin{array}{l}{\left[\left(\mathrm{Re}_{6} \mathrm{Q}_{8}\right)\left(\mathrm{N}_{3}\right)_{6}\right]^{4-}} \\
(\mathrm{Q}=\mathrm{S} \text { or } \mathrm{Se})\end{array}$ & $\begin{array}{l}{\left[\left(\operatorname{Re}_{6} \mathrm{~S}_{8}\right) \mathrm{Br}_{6}\right]^{4-} \text { or }} \\
{\left[\left(\operatorname{Re}_{6} \mathrm{Se}_{8}\right)(\mathrm{OH})_{6}\right]^{4-} \text { and } \mathrm{N}_{3}^{-}}\end{array}$ & $\begin{array}{l}\text { reaction in an aqueous solution at room } \\
\text { temperature, } 24 \mathrm{~h}\end{array}$ & {$[48,114]$} \\
\hline $\begin{array}{l}{\left[\left(\mathrm{Re}_{6} \mathrm{Q}_{8}\right)(\mathrm{OH})_{6}\right]^{4-}} \\
(\mathrm{Q}=\mathrm{S} \text { or } \mathrm{Se})\end{array}$ & $\mathrm{Re}_{6} \mathrm{Q}_{8} \mathrm{Br}_{2}$ and $\mathrm{KOH}$ or $\mathrm{CsOH}$ & $\begin{array}{l}280{ }^{\circ} \mathrm{C}(\text { for } \mathrm{Q}=\mathrm{S}) \text { or } 200-230^{\circ} \mathrm{C}(\text { for } \mathrm{Q}=\mathrm{Se}) \text {, } \\
30 \mathrm{~min}\end{array}$ & {$[115,116]$} \\
\hline $\begin{array}{l}{\left[\left(\mathrm{Re}_{6} \mathrm{Q}_{8}\right)\left(\mathrm{H}_{2} \mathrm{O}\right)_{n}(\mathrm{OH})_{6-}\right.} \\
n]^{n-4} \\
(\mathrm{Q}=\mathrm{S} \text { or } \mathrm{Se}, n=0-6)\end{array}$ & {$\left[\left(\operatorname{Re}_{6} \mathrm{Q}_{8}\right)(\mathrm{OH})_{6}\right]^{4-}$ and $\mathrm{H}^{+}$} & $\begin{array}{l}\text { reaction in an aqueous solution at room } \\
\text { temperature }\end{array}$ & [117] \\
\hline $\begin{array}{l}{\left[\left(\mathrm{Re}_{6} \mathrm{Q}_{8}\right) \mathrm{F}_{6-n}\left(\mathrm{H}_{2} \mathrm{O}\right)_{n}\right]^{n-4}} \\
(\mathrm{Q}=\mathrm{S} \text { or } \mathrm{Se}, n=3 \text { or } 4)\end{array}$ & $\begin{array}{l}{\left[\left(\operatorname{Re}_{6} \mathrm{~S}_{8}\right)(\mathrm{OH})_{6}\right]^{4-} \text { or }} \\
{\left[\left(\operatorname{Re}_{6} \mathrm{Se}_{8}\right)(\mathrm{OH})_{6}\right]^{3-}, \mathrm{F}^{-} \text {and } \mathrm{H}_{2} \mathrm{O}}\end{array}$ & $\begin{array}{l}\text { reaction with molten } \mathrm{KHF}_{2}\left(270-300{ }^{\circ} \mathrm{C}, 2 \mathrm{~h}\right) \\
\text { followed by recrystallization from an aqueous } \\
\text { solution }\end{array}$ & [100] \\
\hline $\begin{array}{l}{\left[\left(\mathrm{Re}_{6} \mathrm{~S}_{8}\right)\left(\mathrm{RCOO}_{6}\right]^{4-}\right.} \\
\left(\mathrm{R}=\mathrm{H} \text { or } \mathrm{CH}_{3}\right)\end{array}$ & {$\left[\left(\mathrm{Re}_{6} \mathrm{~S}_{8}\right)(\mathrm{OH})_{6}\right]^{4-}$ and $\mathrm{RCOO}^{-}$} & $\begin{array}{l}\text { reaction in an aqueous solution at room } \\
\text { temperature }\end{array}$ & {$[42,121]$} \\
\hline $\begin{array}{l}{\left[\left(\mathrm{Re}_{6} \mathrm{Q}_{8}\right)(\mathrm{TBP})_{4}(\mathrm{OH})_{2}\right]} \\
(\mathrm{Q}=\mathrm{S} \text { or } \mathrm{Se}, \mathrm{TBP}=p \text { - } \\
\text { tert-butylpyridine })\end{array}$ & {$\left[\left(\operatorname{Re}_{6} \mathrm{Q}_{8}\right)(\mathrm{OH})_{6}\right]^{4-}$ and TBP } & reflux of an aqueous solution, 2 days & [41] \\
\hline$\left[\left(\mathrm{Re}_{6} \mathrm{~S}_{8}\right)(\mathrm{CN})_{4}(\mathrm{OH})_{2}\right]^{4-}$ & $\mathrm{Cs}_{4}\left[\operatorname{Re}_{6} \mathrm{~S}_{9}(\mathrm{CN})_{4}\right]$ and $\mathrm{KOH}$ & reflux of an aqueous solution, $24 \mathrm{~h}$ & [118]. \\
\hline$\left[\left(\mathrm{Re}_{6} \mathrm{Se}_{8}\right)(\mathrm{CN})_{4}(\mathrm{OH})_{2}\right]^{4-}$ & {$\left[\left(\mathrm{Re}_{6} \mathrm{Q}_{8}\right)(\mathrm{OH})_{6}\right]^{4-}$ and $\mathrm{CN}^{-}$} & reflux of an aqueous solution, $2 \mathrm{~h}$ & [119] \\
\hline
\end{tabular}

In the following, we will focus on new perspectives based on recent work dealing on in-situ synthesis of supramolecular compounds using organic melts and on hydroxo, cyano and cyano-hydro complexes as building blocks for the elaboration of supramolecular frameworks, nanoparticles, liquid crystals and functional surfaces. 


\section{Description of Photophysical Properties}

As described above, during the last two decades, a large number of hexarhenium chalcogenide cluster complexes with various apical ligand environments have been synthesized and their structures and properties were evaluated. Following are summarized some important features about electronic structures, redox and luminescence properties.

\section{Electronic structures and redox properties}

The electronic structures of $\left[\left(\mathrm{M}_{6} \mathrm{~L}_{8}{ }^{\mathrm{i}}\right) \mathrm{L}_{6}{ }_{6}\right]$ clusters were studied by several authors using quantum chemical calculations. The molecular diagram of $\left[\left(\mathrm{M}_{6} \mathrm{~L}_{8}^{\mathrm{i}}\right) \mathrm{L}_{6}{ }_{6}\right]$ units - considering an $O_{h}$ symmetry - shows a set of twelve metal-metal bonding molecular orbitals $\left(a_{1 g}, t_{1 u}, t_{2 g}, t_{2 u}\right.$, and $\left.e_{g}\right)$. The population of these twelve bonding molecular orbitals (MO) corresponding to metal-metal bonds in a metal cluster $\mathrm{Re}_{6}$ leads to an optimum number of valence electrons, the so-called valence electron concentration (VEC) of 24. This corresponds to a rhenium ion with a $\mathrm{d}^{4}$ electron configuration, found in $\left[\left(\operatorname{Re}_{6} \mathrm{Q}_{8}{ }\right) \mathrm{Y}_{6}^{\mathrm{a}}\right]^{4}(\mathrm{Q}=\mathrm{S}$ or $\mathrm{Se} ; \mathrm{Y}=$ halogen, $\mathrm{OH}$ or $\mathrm{CN})$ with a $\left(\operatorname{Re}_{6} \mathrm{Q}_{8}{ }^{2}\right)^{2+}$ cluster core. One-electron oxidation can be easily performed in solutions of molecular rhenium complexes. This corresponds to the removal of one electron from the HOMO level leading to a VEC $=23$. Redox potentials depend on both the nature inner and apical ligands and vary from $0.065 \mathrm{~V}$ for $\left[\left(\operatorname{Re}_{6} \mathrm{Te}_{8}{ }_{8}{ }_{8}\right)(\mathrm{CN})_{6}^{\mathrm{a}}\right]^{4-}$ to $1.01 \mathrm{~V}$ for $\left[\left(\operatorname{Re}_{6} \mathrm{Se}_{8}{ }_{8}\right)(\mu \text {-dpph })^{\mathrm{a}}{ }_{2} \mathrm{I}_{4}^{\mathrm{a}}\right]^{2+}$ moieties [65]. This oxidation provides compounds with paramagnetic cluster. Further oxidation of $\mathrm{Re}_{6}$ cluster was demonstrated in electrochemical experiments but up to now 22 electrons moieties were not isolated as individual phases.

\section{Luminescence properties}

By many examples, it was shown, that complexes of the general formula $\left[\left(\operatorname{Re}_{6} \mathrm{Q}_{8}{ }^{\mathrm{i}}\right) \mathrm{L}_{6}^{\mathrm{a}}\right]^{4-}(\mathrm{Q}=\mathrm{S}$ or $\mathrm{Se} ; \mathrm{L}=$ halogen ion, $\mathrm{CN}^{-}, \mathrm{NCS}^{-}, \mathrm{N}_{3}^{-}, \mathrm{OH}^{-} / \mathrm{H}_{2} \mathrm{O}$, anions of carboxylic acids, pyridine and phosphine derivatives, etc.) with the $\left(\operatorname{Re}_{6} \mathrm{Q}_{8}\right)^{2+}$ core having 24 valence electrons in the solid state and in solutions emit luminescence in visible and near-infrared regions (NIR) upon ultraviolet or blue light excitation with emission lifetimes in the microsecond range [38-42, 44, 48, 49, 81, 86, 88, 101, 102, 113,117, 119, 121, 127, 128]. The spectroscopic and photophysical properties of these complexes have been extensively studied experimentally (see references above) and by theoretical calculations [34, 38, 42, 48, 104-108, 115, 119, 129]. On the basis of the fairly long emission lifetimes and the insensitive nature of the emission spectrum to the type of solvents employed, it has been proposed that the emitting excited state of the hexarhenium (III) complex is a spin-triplet type and involves orbitals that are primarily localized on the $\left(\operatorname{Re}_{6} \mathrm{Q}_{8}\right)^{2+}$ core. In addition to these experimental observations, theoretical studies of the excited state have demonstrated that the lowest-energy unoccupied molecular orbitals (LUMOs) are primarily localized on the $\left(\operatorname{Re}_{6} \mathrm{Q}_{8}\right)^{2+}$ core $[38,42,44,101,108,130,131]$. Among the known $\operatorname{Re}_{6}$ clusters, $\left[\left(\operatorname{Re}_{6} \mathrm{Se}_{8}{ }_{8}\right)(\mathrm{DMSO})_{6}^{\mathrm{a}}\right]^{2+}$ is the strongest luminophore with the emission quantum yield and lifetime in $\mathrm{CH}_{2} \mathrm{Cl}_{2}$ being 0.238 and $22.4 \mu$ s, respectively [127]. Systematical studies of spectroscopic and photophysical properties (emission maximum wavelengths $\lambda_{\mathrm{em}}$, quantum yields $\Phi_{\mathrm{em}}$ and lifetimes $\tau_{\mathrm{em}}$ ) of hexarhenium cluster complexes allowed to reveal some dependencies and make important conclusions, namely:

$1)$ as a rule, the $\left(\operatorname{Re}_{6} \mathrm{Se}_{8}{ }^{\mathrm{i}}\right)^{2+}$-based complexes show a stronger emission than those based on $\left(\operatorname{Re}_{6} \mathrm{~S}_{8}\right)^{2+}$ possessing the same apical ligand environment [38, 40, 127];

2) influence of the nature of apical ligands:

- in the series $\left[\left(\operatorname{Re}_{6} \mathrm{~S}_{8}{ }^{i}\right) \mathrm{X}_{6}^{\mathrm{a}}\right]^{4-}\left(\mathrm{X}=\mathrm{Cl}^{-}, \mathrm{Br}^{-}\right.$or I- $)$the emission maximum shifts to a longer wave-length while $\Phi_{\mathrm{em}}$ and $\tau_{\mathrm{em}}$ decrease as the terminal halide ions become heavier [39];

- in $\mathrm{CH}_{2} \mathrm{Cl}_{2}$ solutions complexes with oxygen- or nitrogen-based organic ligands (DMSO, DMF, pyridine, acetonitrile) as well as the chalcocyanides $\left[\left(\operatorname{Re}_{6} \mathrm{Q}_{8}{ }_{8}\right)(\mathrm{CN})^{\mathrm{a}}{ }_{6}\right]^{-}$deliver maximal quantum yields and the longest lifetimes and tend to the higher-energy emission, while clusters having six soft, polarizable ligands, such as iodide or bromide, emit with less intensity, shorter lifetimes, and redder luminescence. Phosphine ligation ( $\left.\mathrm{PEt}_{3}\right)$ also diminishes $\Phi_{\mathrm{em}}[38,127]$;

- in-depth study of the series of complexes with different $\mathrm{N}$-heteroaromatic ligands demonstrated that the emission is effectively quenched as the result of $\left(\operatorname{Re}_{6} \mathrm{Q}^{\mathrm{i}} 8\right)^{2+}$-to-ligand charge transfer (MLCT) if the ligand (such as 4,4'-bipyridine or pyrazine) has free nitrogen sites [44, 101];

- mixed-ligand cyanohydroxo complexes trans- $\left[\left(\operatorname{Re}_{6} \mathrm{Q}_{8}{ }^{\mathrm{i}}\right)(\mathrm{CN})^{\mathrm{a}}{ }_{4}(\mathrm{OH})^{\mathrm{a}}{ }_{2}\right]^{4-}(\mathrm{Q}=\mathrm{S}$ or Se) in aqueous solutions exhibit the emission spectra and photophysical characteristics appreciably different from hexahydroxo clusters $\left[\left(\operatorname{Re}_{6} \mathrm{Q}_{8}{ }_{8}\right)(\mathrm{OH})_{6}{ }_{6}\right]^{4-}$ and at the same time very similar to the corresponding hexacyano ones $\left[\left(\operatorname{Re}_{6} \mathrm{Q}_{8}{ }^{\mathrm{i}}\right)(\mathrm{CN})^{\mathrm{a}}{ }_{6}\right]^{4-}[49,119]$ 
- the acidification of an aqueous solution with $\left[\left(\mathrm{Re}_{6} \mathrm{Q}_{8}{ }_{8}\right)(\mathrm{OH})_{6}{ }_{6}\right]^{4-}(\mathrm{Q}=\mathrm{S}$ or Se) ions leads to transformation of the anionic cluster to $\left[\left(\mathrm{Re}_{6} \mathrm{Q}_{8}{ }_{8}\right)\left(\mathrm{H}_{2} \mathrm{O}\right)_{x}{ }_{x}(\mathrm{OH})_{6-x}{ }^{\mathrm{a}}\right]^{x-4}$ through the protonation of the apical hydroxo ligands accompanied by red shift of $\lambda_{\mathrm{em}}$ and irregular changes in $\Phi_{\mathrm{em}}$ and $\tau_{\mathrm{em}}$ values [117]. Whereas, spectroscopic and photophysical properties of cyanohydroxo complexes trans $-\left[\left(\operatorname{Re}_{6} \mathrm{Q}_{8}{ }_{8}\right)(\mathrm{CN})^{\mathrm{a}}{ }_{4}(\mathrm{OH})^{\mathrm{a}}{ }^{2}\right]^{4-}$ and hexacyano ones $\left[\left(\operatorname{Re}_{6} \mathrm{Q}_{8}{ }_{8}\right)(\mathrm{CN})^{\mathrm{a}}{ }_{6}\right]^{4-}$ are completely insensitive to $\mathrm{pH}$ of their aqueous solutions, demonstrating that the luminescence properties of trans- $\left[\left(\operatorname{Re}_{6} \mathrm{Q}_{8)}{ }_{8}(\mathrm{CN})_{4}^{\mathrm{a}}(\mathrm{OH})^{\mathrm{a}}{ }_{2-x}\left(\mathrm{H}_{2} \mathrm{O}\right)^{\mathrm{a}}{ }_{x}\right]^{x-4}\right.$ are mainly defined by the $\mathrm{CN}^{-}$ligands and not appreciably affected by the $\mathrm{OH}^{-}$or $\mathrm{H}_{2} \mathrm{O}$ ligand(s) $[49,119]$;

3 ) the quantum yield and lifetimes significantly depend on a solvent while the emission maximum remains the same. In particular, a complex in a deaerated aqueous solution shows much lower $\Phi_{\mathrm{em}}$ and $\tau_{\mathrm{em}}$ values than in a deaerated organic solvent that can be explained by interaction of water molecules with the inner chalcogenide ligands providing more efficient vibrational decay pathway of the excited state [40];

4) the dependences of photophysical properties on both the inner and apical ligands were discussed in terms of the energy gap law, by which the natural logarithm of the nonradiative decay rate constant $\left(\mathrm{k}_{\mathrm{nr}}\right)$ of a cluster is inversely proportional to the emission maximum energy. Since it was found that the emission lifetime of the cluster is determined mainly by the $\mathrm{k}_{\mathrm{nr}}$ value, the energy gap dependence of $\mathrm{k}_{\mathrm{nr}}$ demonstrates that the emission lifetime of a cluster can be predicted approximately from the emission energy [38, 40, 113, 127];

5) solid-state emission lifetimes and quantum yields usually occupy a similar range at room temperature [38, 42, $44,48,88,113,119,121]$. Low-temperature luminescence experiments indicate a progressive red shift of the emission maximum upon cooling, with an increase in the excited-state lifetime and the emission quantum yield $[38,44,89,113]$;

6) the long lifetimes, large Stokes shifts, and excited-state quenching by $\mathrm{O}_{2}$ indicate the spin-triplet nature of the luminescent excited state of the cluster complexes, i.e. the change in spin multiplicity is involved in the electronic transitions $[38,39,86,89]$. Note that to date there is only one described example of a luminescent $\left(\operatorname{Re}_{6} \operatorname{Te}_{8}{ }^{\mathrm{i}}\right)^{2+}$-based complex, namely the photoluminescence of the complex $\left[\left(\operatorname{Re}_{6} \operatorname{Te}_{8}{ }_{8}\right)(\mathrm{CN})_{6}^{\mathrm{a}}\right]^{4-}$ has been studied in acetonitrile and aqueous solutions and it was shown, that the telluride cluster shows much weaker and shortlived emission comparing to $\left[\left(\operatorname{Re}_{6} \mathrm{~S}_{8}{ }_{8}\right)(\mathrm{CN})_{6}{ }_{6}\right]^{4-}$ and $\left[\left(\operatorname{Re}_{6} \mathrm{Se}_{8}{ }_{8}\right)(\mathrm{CN})_{6}^{\mathrm{a}}\right]^{4-}[40]$. The lack of data on luminescence of telluride hexarhenium cluster complexes with other apical ligands is a consequence of the fact that the tellurocyanide complex is still the unique representative of soluble $\left(\operatorname{Re}_{6} \mathrm{Te}_{8}{ }^{\mathrm{i}}\right)^{2+}$-based complex.

The luminescence properties of $\mathrm{Re}_{6}$ cluster complexes provided an incentive to establish their potential applications [61, 81, 88, 90, 132]. Synthetic flexibility of the apical ligand environment affords a range of clusters for developing innovative luminescent materials. The quenching of the phosphorescence by $\mathrm{O}_{2}$ suggests applications to optical sensor technology and singlet oxygen generation that can be used, for example, in the photodynamic therapy of cancer.

\section{Molten salt approach: Toward the one pot synthesis of supramolecular frameworks}

It was found that reactions between chalcohalogenide hexarhenium cluster complexes and some molten organic compounds which can coordinate to rhenium lead to substitution of some apical halogen atoms by the organic units [43, 129, 133-136]. Such approach allows to produce cluster complexes with functional organic ligand environment in high yield. The reactions in a molten organic medium may result in two types of cluster complexes: partially substituted neutral complexes $[43,129,135,136]$ or hexasubstituted cluster cations $[133$, 134]. However, so far there is no evidence on the nature of the driving force at the origin of formation of neutral (partially substituted) or cationic (hexasubstituted) complexes.

The cations $\left[\left(\operatorname{Re}_{6} \mathrm{Q}_{8}{ }^{i}\right)\left(3,5-\mathrm{Me}_{2} \mathrm{PzH}\right)_{6}^{\mathrm{a}}\right]^{2+}$ (Fig. 2a) were obtained by the reaction of rhenium thiobromide $\left[\left(\operatorname{Re}_{6} \mathrm{~S}_{8}{ }_{8}\right) \mathrm{Br}_{6}{ }_{6}\right]^{4-}$ or selenobromide $\left[\left(\operatorname{Re}_{6} \mathrm{Se}_{8}{ }_{8}\right) \mathrm{Br}_{6}{ }_{6}\right]^{3-}$ complex with molten 3,5-dimethylpyrazole (3,5-Me $\left.2 \mathrm{PzH}\right)$ and separated as salts $\left[\left(\operatorname{Re}_{6} \mathrm{Q}_{8}{ }^{i}\right)\left(3,5-\mathrm{Me}_{2} \mathrm{PzH}\right)_{6}^{\mathrm{a}}\right] \mathrm{Br}_{2} \cdot 2\left(3,5-\mathrm{Me}_{2} \mathrm{PzH}\right)$. In the crystal structures each cluster cation is accompanied by two $\mathrm{Br}^{-}$anions and additionally by two molecules of $3,5-\mathrm{Me}_{2} \mathrm{PzH}$. An extensive system of hydrogen bonds joins these ionic fragments and molecules 3,5- $\mathrm{Me}_{2} \mathrm{PzH}$ to one another. The interactions of the given type include $\mathrm{N}-\mathrm{H} \cdots \mathrm{N}$ bonds between coordinated and uncoordinated molecules of $3,5-\mathrm{Me}_{2} \mathrm{PzH} ; \mathrm{N}-\mathrm{H} \cdots \mathrm{Br}$ bonds between coordinated molecules of $3,5-\mathrm{Me}_{2} \mathrm{PzH}$ and $\mathrm{Br}^{-}$anions and $\mathrm{N}-\mathrm{H} \cdots \mathrm{Br}$ bonds between uncoordinated molecules of 3,5- $\mathrm{Me}_{2} \mathrm{PzH}$ and $\mathrm{Br}^{-}$anions [134]. 


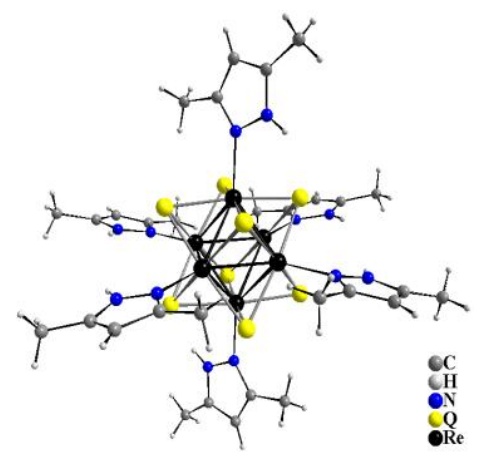

a)

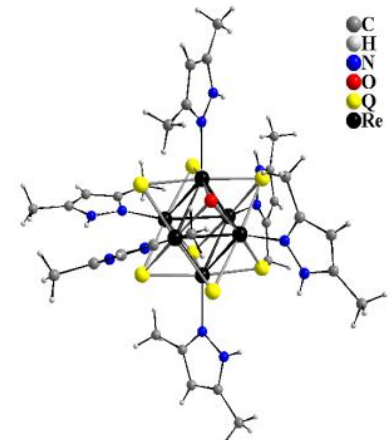

b)

Fig. 2 Structure of cationic cluster complexes $\left[\left(\operatorname{Re}_{6} Q_{8}{ }\right)\left(3,5-\mathrm{Me}_{2} \mathrm{PzH}\right)_{6}{ }_{6}{ }^{2+}(\mathrm{a})\right.$ and $\left[\left(\operatorname{Re}_{6} \mathrm{Q}_{7}{ }_{7} \mathrm{O}^{\mathrm{i}}\right)\left(3,5-\mathrm{Me}_{2} \mathrm{PzH}\right)_{6}\right]^{2+}(\mathrm{b})$

Two octahedral rhenium cluster complexes $\left[\left(\mathrm{Re}_{6} \mathrm{Q}_{7}{ }_{7} \mathrm{O}^{\mathrm{i}}\right)(3,5-\mathrm{Me} 2 \mathrm{PzH})_{6}^{\mathrm{a}}\right]^{2+}$ (Fig. 2b) were obtained also from molten 3,5- $\mathrm{Me}_{2} \mathrm{PzH}$ by the reaction with rhenium chalcobromides $\left[\left(\operatorname{Re}_{6} \mathrm{Q}_{7}^{\mathrm{i}} \mathrm{Br}^{\mathrm{i}}\right) \mathrm{Br}_{6}{ }_{6}^{3-}(\mathrm{Q}=\mathrm{S}, \mathrm{Se})\right.$ possessing the mixed-ligand cluster core $\left(\operatorname{Re}_{6} \mathrm{Q}_{7}{ }_{7} \mathrm{Br}^{\mathrm{i}}\right)^{3+}$. It was found that during the reaction substitution of six apical bromide ligands by $3,5-\mathrm{Me}_{2} \mathrm{PzH}$ molecules accompanied by substitution of the inner $\mu_{3}-\mathrm{Br}$ ligand by oxygen giving cluster cores $\left(\operatorname{Re}_{6} \mathrm{Q}_{7} \mathrm{O}^{\mathrm{i}}\right)^{2+}$. Note that there is no disorder in the present structures: seven corner positions of the $\mathrm{Q}_{7} \mathrm{O}$ cube are occupied exclusively by $\mathrm{S}$ or Se atoms and one by an $\mathrm{O}$ atom. There are two types of $\mathrm{Br}$ atoms in the structure: one bromine atom is connected by hydrogen bonds to one cluster whereas the other one is bridged between two cluster cations to form extended chains along the $a$-axes [133].

A series of partially substituted neutral complexes $\left[\left(\mathrm{Re}_{6} \mathrm{Q}_{8-n}^{\mathrm{i}} \mathrm{Br}_{n}^{\mathrm{i}}\right)\left(\mathrm{EPh}_{3}\right)^{\mathrm{a}}{ }_{4 n} \mathrm{Br}^{\mathrm{a}}{ }_{\mathrm{n}+2}\right](\mathrm{Q}=\mathrm{S}, n=0,1$ or 2 ; Q $=\mathrm{Se}, n=0$ or 1$)$ were obtained by the reaction between anionic chalcobromide complexes $\left[\left(\operatorname{Re}_{6} \mathrm{Q}_{8-n}^{\mathrm{i}} \mathrm{Br}_{n}^{\mathrm{i}}\right) \mathrm{Br}^{\mathrm{a}}{ }_{6}\right]^{4-n}$ and molten $\mathrm{EPh}_{3}(\mathrm{E}=\mathrm{P}, \mathrm{As}$ or $\mathrm{Sb})[129,135]$. More precisely, reactions of $\left[\left(\operatorname{Re}_{6} \mathrm{Q}_{8}{ }_{8}\right) \mathrm{Br}_{6}^{\mathrm{a}}\right]^{\mathrm{x}-}(\mathrm{Q}=\mathrm{S}, x=4 ; \mathrm{Q}=$ Se, $x=3)$ and $\left[\left(\operatorname{Re}_{6} \mathrm{Q}_{7} \mathrm{Br}^{\mathrm{i}}\right) \mathrm{Br}_{6}^{\mathrm{a}}\right]^{3-}$ and molten $\mathrm{EPh}_{3}$ resulted in trans-[( $\left.\left.\operatorname{Re}_{6} \mathrm{Q}_{8}{ }_{8}\right)\left(\mathrm{EPh}_{3}\right)_{4}{ }_{4} \mathrm{Br}^{\mathrm{a}}{ }_{2}\right]$ and fac$\left[\left(\mathrm{Re}_{6} \mathrm{Q}_{7}{ }_{B r}{ }^{\mathrm{i}}\right)\left(\mathrm{EPh}_{3}\right)_{3}{ }_{3} \mathrm{Br}_{3}^{\mathrm{a}}\right]$, respectively (Fig. 3a,b); $\left[\left(\mathrm{Re}_{6} \mathrm{~S}_{6}{ }_{6} \mathrm{Br}_{2}{ }_{2}\right) \mathrm{Br}_{6}{ }_{6}\right]^{2-}$ and molten $\mathrm{PPh}_{3}$ produced a mixture cis$\left[\left(\mathrm{Re}_{6} \mathrm{~S}_{6}{ }_{6} \mathrm{Br}_{2}{ }_{2}\right)\left(\mathrm{PPh}_{3}\right)_{2}{ }_{2} \mathrm{Br}_{4}^{\mathrm{a}}\right]$ and trans- $\left[\left(\mathrm{Re}_{6} \mathrm{~S}_{6}{ }_{6} \mathrm{Br}_{2}{ }_{2}\right)\left(\mathrm{PPh}_{3}\right)^{\mathrm{a}}{ }_{2} \mathrm{Br}_{4}^{\mathrm{a}}{ }_{4}\right]$ (Fig. 3c,d), that were separated by column chromatography. The interesting feature of these structures is the ligand ordering in mixed chalcobromide cluster cores $\left(\operatorname{Re}_{6} \mathrm{Q}_{7}{ }_{7} \mathrm{Br}^{\mathrm{i}}\right)^{3+}$ and $\left(\operatorname{Re}_{6} \mathrm{~S}_{6} \mathrm{Br}_{2}\right)^{{ }^{4+}}$. Note that the neutral complexes with mixed-ligand apical ligand environment were obtained in reactions with a large excess of $\mathrm{EPh}_{3}$. It was expected that the reactions result in the substitution of all terminal bromide ligands in the starting cluster compounds by $\mathrm{EPh}_{3}$ ligands similarly to reactions with an excess of molten 3,5-dimethylpyrazole described above. However, complexes obtained in the reactions with $\mathrm{EPh}_{3}$ have only four, three, or even two terminal $\mathrm{EPh}_{3}$ ligands depending on the composition (and consequently, the charge) of cluster core. Such results were explained by the preferred formation of neutral molecular compounds in this system. No remarkable interactions were found between the molecular complexes in all these crystal structures of cluster complexes with $\mathrm{EPh}_{3}$ ligands.

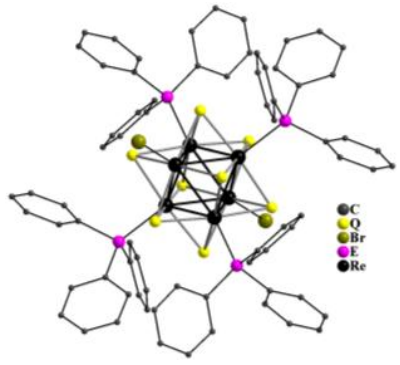

a)

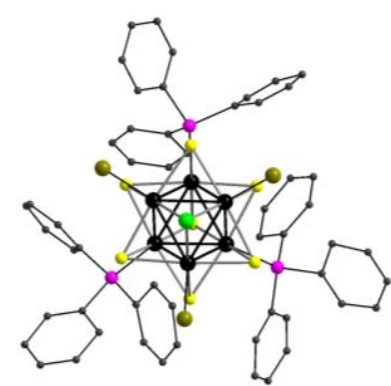

b) 


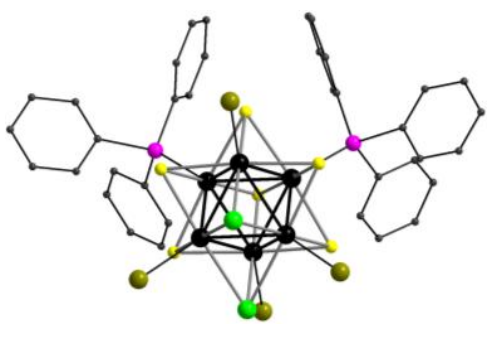

c)

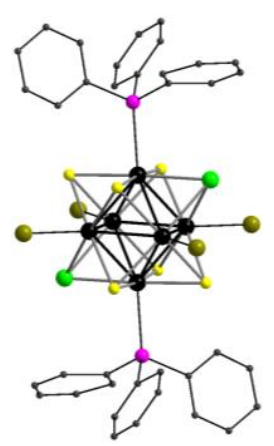

d)

Fig. 3 Structure of neutral cluster complexes trans-[( $\left.\left.\operatorname{Re}_{6} \mathrm{Q}^{\mathrm{i}}{ }\right)\left(\mathrm{EPh}_{3}\right)^{\mathrm{a}}{ }_{4} \mathrm{Br}^{\mathrm{a}}{ }_{2}\right]$ (a), fac- $\left[\left(\operatorname{Re}_{6} \mathrm{Q}_{7}{ }_{7} \mathrm{Br}^{\mathrm{i}}\right)\left(\mathrm{EPh}_{3}\right)^{\mathrm{a}}{ }_{3} \mathrm{Br}^{\mathrm{a}}{ }_{3}\right]$ (b), cis$\left[\left(\operatorname{Re}_{6} \mathrm{~S}_{6}{ }_{6} \mathrm{Br}_{2}{ }_{2}\right)\left(\mathrm{PPh}_{3}\right)^{\mathrm{a}}{ }_{2} \mathrm{Br}_{4}^{\mathrm{a}}\right]$ (c) and trans-[( $\left.\left.\operatorname{Re}_{6} \mathrm{~S}_{6}{ }_{6} \mathrm{Br}_{2}^{\mathrm{i}}\right)\left(\mathrm{PPh}_{3}\right)_{2}{ }_{2} \mathrm{Br}^{\mathrm{a}}{ }_{4}\right](\mathrm{d})$

By the example of reaction with molten pyrazine it was shown that functional $\operatorname{Re}_{6}$ cluster units can be obtained by a direct interaction of cluster chalcohalogenides with molten organic ligands based on organic ring containing nitrogen atoms [43]. Such one pot synthesis enables an easier preparation of functional units and do not need a preliminary functionalization of the cluster precursor before self-assembling from solutions as shown in the strategies developed by R. H. Holm, Z. Zheng and T. Yoshimura who oxidized parent chalcohalogenide cluster complexes $[37,96,101,103]$. It turns out that the number of substituted apical ligands depends on the charge of the unit in the starting precursor. The easy formation of the stable $\mathrm{CsBr}$ inorganic salt in the organic melt must be the key point of this reaction. The limiting factor of the technique is the thermal stability of organic ligands that can decompose before the exchange occurs. Among organic ligands stable at mild temperatures, bidentate linkers such as, for instance, bipyridine or pyrazine constitute relevant candidates to build coordination polymers with low dimensionalities or supramolecular frameworks. One of the actual hot topics is the research of porous neutral supramolecular frameworks. A possible strategy is the reaction of cluster unit leading to more than two substituted apical sites. It is clear that substitution of one halide ligand by a functional organic moiety can lead to the formation of dimers, while two substituted complexes should lead to the formation of chains. Thus, we can suppose that cluster units with charges of 3- or 4- should lead to the formation of supramolecular frameworks by relevant choice of ligands. In this frame, reactions of $\left[\left(\operatorname{Re}_{6} \mathrm{Q}_{7}{ }_{7} \mathrm{Br}^{\mathrm{i}}\right) \mathrm{Br}^{\mathrm{a}}{ }_{6}\right]^{3-}$ with molten pyrazine were investigated. After the optimization procedure, it turned out that reactions at $140{ }^{\circ} \mathrm{C}$ for 2 days in sealed glass tubes afforded very interesting supramolecular compounds built up from octahedral rhenium cluster complexes $f a c-\left[\left(\operatorname{Re}_{6} \mathrm{Q}_{7}{ }_{7} \mathrm{Br}^{\mathrm{i}}\right)\left(\mathrm{pyz}^{\mathrm{a}}{ }_{3} \mathrm{Br}^{\mathrm{a}}{ }_{3}\right](\mathrm{Q}=\mathrm{S}, \mathrm{Se})\right.$ (Fig. 4a). Despite their bidentate nature, each pyrazine is bonded to only one $\operatorname{Re}_{6}$ cluster. Indeed, this finding evidenced that the idea to link cluster units together via simple bidentate ligands containing aromatic groups is counter balanced by the formation of strong supramolecular interactions (i.e. hydrogen bonding and $\pi-\pi$ stacking). But at the end, fortunately the structures of fac $-\left[\left(\mathrm{Re}_{6} \mathrm{Q}_{7}{ }_{7} \mathrm{Br}^{\mathrm{i}}\right)(\mathrm{pyz})_{3}^{\mathrm{a}} \mathrm{Br}_{3}^{\mathrm{a}}{ }_{3}\right] \cdot \mathrm{xH}_{2} \mathrm{O}$ have porous structures containing hollow tubular channels (Fig. 4b). The $\left(\operatorname{Re}_{6} \mathrm{Q}_{7}{ }_{7} \mathrm{Br}^{\mathrm{i}}\right)^{3+}$ cluster core is built up from a $\operatorname{Re}_{6}$ cluster lying in a cube of ligands formed by seven $\mathrm{Q}$ 's and one $\mathrm{Br}$. It is worth noting that, in the structures of starting salts $\mathrm{Cs}_{3}\left[\left(\operatorname{Re}_{6} \mathrm{Q}_{7}{ }_{7} \mathrm{Br}^{\mathrm{i}}\right) \mathrm{Br}_{6}^{\mathrm{a}}\right] \cdot \mathrm{H}_{2} \mathrm{O}$ the seven Q's and $\mathrm{Br}$ are randomly distributed on the eight inner positions of the anionic cluster complex. The presence of only one $\mathrm{Br}$ atom among the inner ligands generates the local $C_{3 V}$ symmetry for the $\left[\left(\operatorname{Re}_{6} \mathrm{Q}_{7}^{\mathrm{i}} \mathrm{Br}\right)^{\mathrm{i}} \mathrm{Br}_{6}\right]^{3-}$ unit and does not enable the formation of isomers. Thus, owing to the orientational disorder, the average apparent symmetry of the $\left[\left(\operatorname{Re}_{6} \mathrm{Q}_{7}{ }_{7} \mathrm{Br}^{\mathrm{i}}\right) \mathrm{Br}_{6}^{\mathrm{a}}\right]^{3-}$ unit in $\mathrm{Cs}_{3}\left[\left(\mathrm{Re}_{6} \mathrm{Q}_{7}{ }_{7} \mathrm{Br}^{\mathrm{i}}\right) \mathrm{Br}_{6}^{\mathrm{a}}\right] \cdot \mathrm{H}_{2} \mathrm{O}$ deduced from X-ray single crystal diffraction analysis is close to $O_{h}$. In $f a c-\left[\left(\operatorname{Re}_{6} \mathrm{Q}_{7}{ }_{7} \mathrm{Br}^{\mathrm{i}}\right)(\mathrm{pyz})_{3}^{\mathrm{a}} \mathrm{Br}^{\mathrm{a}}{ }_{3}\right] \cdot \mathrm{xH}_{2} \mathrm{O}$, the $\left[\left(\mathrm{Re}_{6} \mathrm{Q}_{7}{ }_{7} \mathrm{Br}^{\mathrm{i}}\right)(\mathrm{pyz})_{3}^{\mathrm{a}} \mathrm{Br}^{\mathrm{a}}\right]^{0}$ complex is not submitted to an orientational disorder, and the local $C_{3 V}$ of the unit symmetry is preserved. The ordering of $\mu_{3}-\mathrm{Br}$ atoms in the fac $-\left[\left(\operatorname{Re}_{6} \mathrm{Q}_{7}{ }_{7} \mathrm{Br}^{\mathrm{i}}\right)(\mathrm{pyz})_{3}^{\mathrm{a}} \mathrm{Br}^{\mathrm{a}}{ }_{3}\right] \cdot \mathrm{xH}_{2} \mathrm{O}$ hybrid structure is driven by the selective substitution of three apical bromines by three pyrazine groups. One of the explanations of this selective ligand coordination is the specific distribution of electron density on the rhenium atoms in the starting precursor. Indeed, owing to the metal-to-ligand charge transfers, charge balances, and the stronger $\mathrm{Re}-\mathrm{Q}^{\mathrm{i}}$ bond compared to the $\mathrm{Re}-\mathrm{Br}^{\mathrm{i}}$ one, the three rhenium atoms bonded to four $\mu_{3}$-chalcogen ligands have a more positive charge than the three rhenium atoms bonded to three $\mu_{3}$-chalcogen and one $\mu_{3}$-halogen atom. The result is that the three $\mathrm{Re}-\mathrm{Br}^{\mathrm{a}}$ bonds for which $\mathrm{Re}$ atoms are exclusively bonded to inner $\mu_{3}-\mathrm{S}$ are weaker than the three opposite $\mathrm{Re}-\mathrm{Br}^{\mathrm{a}}$ ones favoring their substitution by the neutral pyrazine ligands. This affords the $f a c$ isomer of a neutral trisubstituted hybrid unit with an ambivalent inorganic/organic character. The self-assembly of the latter building blocks leads to the formation of a unique structure in which the blocks are held together by halogen/chalcogen van der Waals contacts found in pure inorganic solids along with $\pi-\pi$ stacking and hydrogen bonds found in organic solids. Each cluster interacts with three adjacent ones through $\pi-\pi$ stacking interactions as well as $\mathrm{C}-\mathrm{H} \cdot \cdot \mathrm{N}$ bonds between pyrazine rings, 
building a zigzag hexagonal layer of clusters. The cluster layers fit together according to an AA'A sequence. Interactions between layers occur via $(i)$ van der Waals contacts between $\mu_{3}-\mathrm{Q}^{\mathrm{i}}$ and $\mu_{3}-\mathrm{Br}^{\mathrm{i}}$ along the $c$ axis; (ii) van der Waals contacts between $\mu_{3}-\mathrm{Q}$ and $\mu_{3}-\mathrm{Q}$ and between $\mu_{3}-\mathrm{Br}$ and $\mu_{3}-\mathrm{Br}$ of three adjacent cluster units lying in the same plane but belonging to two successive layers; and (iii) $\mathrm{N}-\mathrm{H} \cdot \cdots \mathrm{N}, \mathrm{C}-\mathrm{H} \cdot \cdots \mathrm{Br}^{\mathrm{a}}$, and $\mathrm{C}-\mathrm{H} \cdot \cdots \mathrm{Br}^{\mathrm{i}}$ bonds. Note that the inner chalcogen atoms are not involved in $\mathrm{C}-\mathrm{H} \cdot \cdots \mathrm{Q}^{\mathrm{i}}$ nor $\mathrm{N}-\mathrm{H} \cdot \cdots \mathrm{S}^{\mathrm{i}}$ bonds, whereas all bromine ligands are involved in hydrogen bonds. Indeed, the formation of a robust hydrogen network involving $\mu_{3}-\mathrm{Br}^{\mathrm{i}}$ must be a driving force that contributes to the $\mathrm{Q} / \mathrm{Br}$ ordering. The $\mathrm{AA}^{\prime} \mathrm{A}$ packing of layers generates large tubular channels parallel to the $c$ axis that are arranged according to a honeycomb disposition imposed by the trigonal symmetry of the $f a c-\left[\left(\operatorname{Re}_{6} \mathrm{Q}_{7}^{\mathrm{i}} \mathrm{Br}^{\mathrm{i}}\right)(\mathrm{pyz})_{3}^{\mathrm{a}} \mathrm{Br}_{3}{ }_{3}\right]$ cluster unit. The effective aperture of the channel is found roughly equal to 6.10 and $6.43 \AA$ for $\mathrm{Q}=\mathrm{S}$ and $\mathrm{Se}$, respectively. The total free volume of the unit cell was found to be $43 \%$, whereas the free volume available for solvent molecules is $29 \% \cdot \mathrm{H}_{2} \mathrm{O}$ molecules can easily be adsorbed through $\mathrm{C}-\mathrm{H} \cdot \cdots \mathrm{O}, \mathrm{O}-\mathrm{H} \cdot \cdots \mathrm{Q}^{\mathrm{i}}$, or $\mathrm{O}-\mathrm{H} \cdot \cdots \mathrm{Br}^{\mathrm{a}}$ bonds. They have no effect in the stabilization of the structure and can be removed without collapsing the structures.

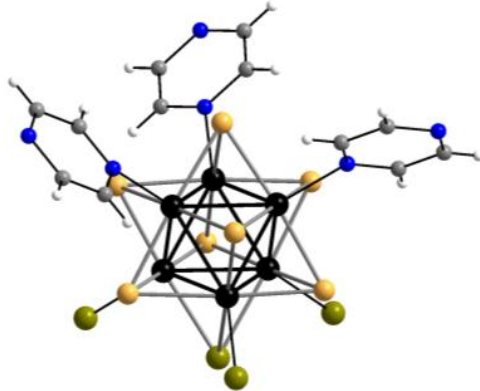

a)

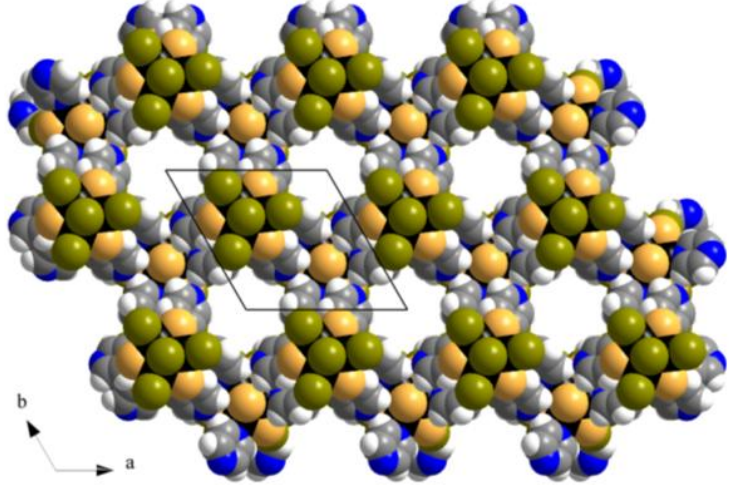

b)

Fig. 4 Structure of neutral cluster complexes $f a c-\left[\left(\operatorname{Re}_{6} \mathrm{Q}_{7}{ }_{7} \mathrm{Br}^{\mathrm{i}}\right)(\mathrm{pyz})^{\mathrm{a}} \mathrm{Br} \mathrm{a}_{3}\right]$ (a) and projection of structure of $f a c$ $\left[\left(\operatorname{Re}_{6} \mathrm{Q}_{7}{ }_{7} \mathrm{Br}^{\mathrm{i}}\right)(\mathrm{pyz})^{\mathrm{a}}{ }_{3} \mathrm{Br}^{\mathrm{a}}{ }_{3}\right] \cdot \mathrm{xH}_{2} \mathrm{O}$ along the $c$ direction (b).

This strategy offers now new perspectives in the design of porous framework containing metal atom clusters. The choice of the precursor determines the level of substitution and the choice of ligand determines the type of supramolecular interactions whilst their size should enable to control the aperture of the pores.

\section{Hybrid organic-inorganic nanocomposites and functional surfaces}

\section{V.a. Hybrid copolymers}

Despite visible emission and interesting properties for displays and lighting, the direct use of solid state compounds for applications is limited because of their ceramic nature (brittle, low plasticity). One solution to overcome this drawback is the sintering processing under inert atmosphere however such method drastically limits the size of the targeted devices. Another strategy is the use of hybrid organic-inorganic technologies that associate an organic matrix with photochemically active and reinforcing inorganic moieties. Hybrid materials obtained by this way have enhanced properties and combine the processability of the organic matrix with the intrinsic properties of the inorganic moieties. For luminescent cluster containing hybrid copolymers, it is important to find the best cluster/polymer weight ratio in order to optimize the optical properties without altering significantly the host matrix processability. Recently, luminescent clusters containing co-polymers have demonstrated their high applicative potential in technologies needing deep red emission. For instance, it has been showed that the luminescence of the trivalent $\operatorname{Er}$ (III) luminescence used in C-band telecom technologies is sensitized by metal atom clusters [137]. A major difficulty in the elaboration of hybrid polymers, is to avoid the segregation of the organic and inorganic phases. One possible strategy to tackle this problem is to maximize the interactions between both parts of the material by modifying the inorganic moieties with polymerizable ligands and copolymerize them with organic monomers. Two examples have been described up to now in which materials have been obtained by copolymerization of functionalized $\operatorname{Re}_{6}$ clusters with an organic matrix. The first one is a copolymer resulting from the copolymerization of $\left.\left[\left(\operatorname{Re}_{6} \operatorname{Se}_{8}{ }_{8}\right)\left(\mathrm{PEt}_{3}\right)_{5}{ }_{5} \text { (4-vinylpyridine }\right)^{\mathrm{a}}\right]^{2+}$ with styrene [138]. Although a mono functionalized cluster seems the best way to introduce clusters without altering significantly the mechanical properties of the organic host because monofunctionalization does not imply cross linking, the major drawbacks of this technique are that it requests the synthesis of non-stable $\operatorname{Re}_{6}$ intermediates, 
tedious purifications of pentafunctionalized building blocks leading finally to an overall synthetic scheme with poor yield. Moreover, optical properties of such copolymer were not reported. This fact could be eventually explained by the presence of five phosphine ligands around the $\mathrm{Re}_{6}$ core that have the unfortunate ability to drastically decrease the luminescence ability of the metallic $\mathrm{Re}_{6}$ core. To prepare new luminescent materials directed towards optical applications, poly-(methyl methacrylate) (PMMA) is a relevant matrix because of its excellent optical properties (i.e., transparency from the near-UV to the near-IR regions), good mechanical and electrical properties, thermal stability, water resistance, and easy shaping. The embedding of $\operatorname{Re}_{6}$ clusters was performed by a prior functionalization with methacrylate (MA) by reaction of $\left[\left(\operatorname{Re}_{6} \mathrm{Q}_{8}{ }^{\mathrm{i}}\right)(\mathrm{tbp})^{\mathrm{a}}{ }_{4}(\mathrm{OH})^{\mathrm{a}}{ }_{2}\right]^{0}$ cluster units with methacrylic acid to form $\left[\left(\operatorname{Re}_{6} \mathrm{Q}_{8}{ }_{8}\right)(\mathrm{tbp})^{\mathrm{a}}{ }_{4}(\mathrm{MA})^{\mathrm{a}}{ }_{2}\right]$.
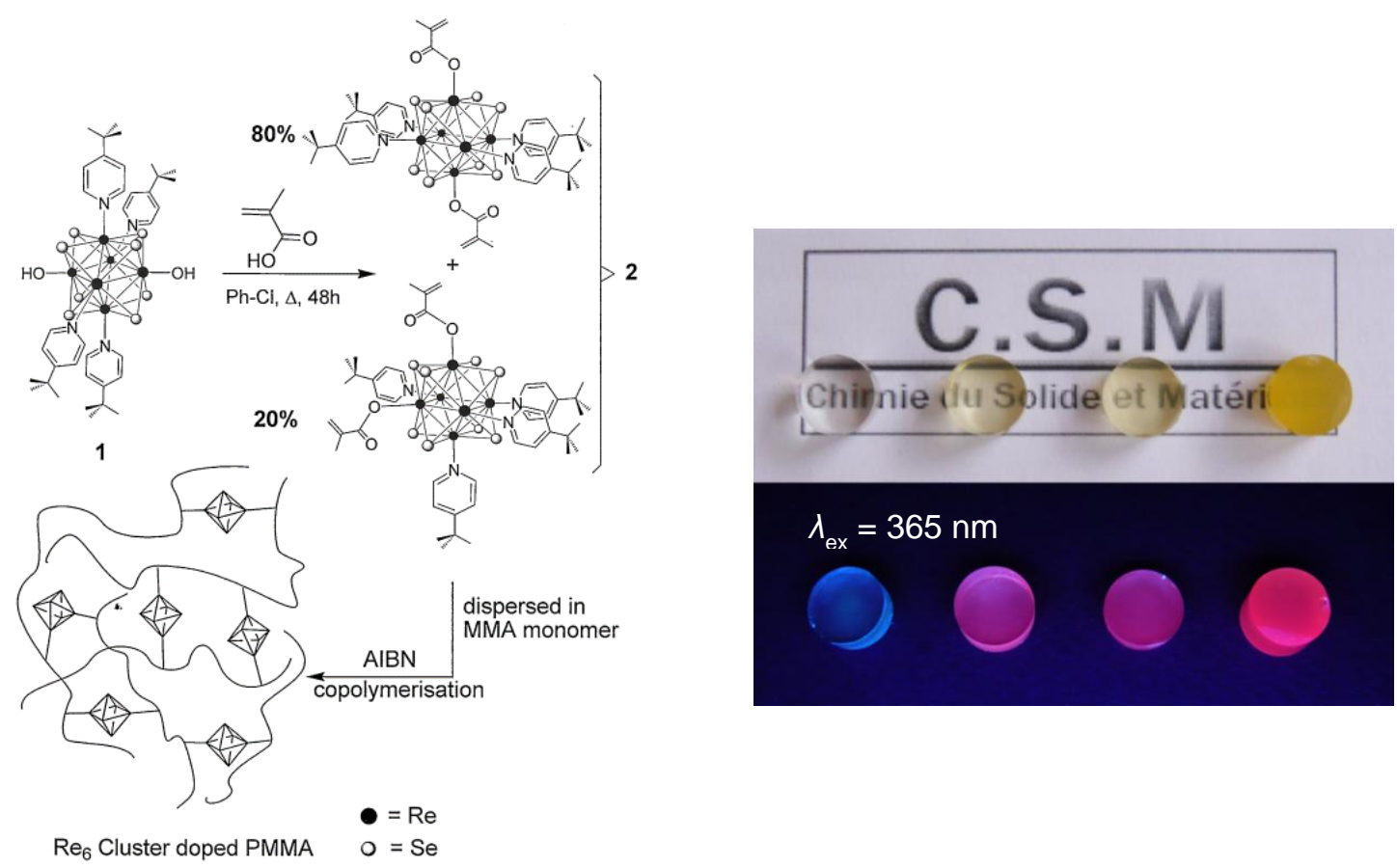

Fig. 5 a) Synthetic pathway for the preparation of the Re6-doped PMMA hybrid material. b) Digital photographs of the PMMA and $\mathrm{Re}_{6}-$ PMMA pellets obtained by bulk synthesis. Top: under normal daylight; bottom: under UV irradiation at $\lambda_{\mathrm{ex}}$ $=365 \mathrm{~nm}$. The weight percentage of clusters increases from left to right: 0, 0.025, 0.05, and $0.1 \mathrm{wt} \%$, respectively. Reprinted from [88] with permission from John Wiley and Sons.

Copolymers with different cluster content were then prepared to optimize the synergy between the processability and transparency of the organic matrix and the high luminescence of the $\operatorname{Re}_{6}$ cluster core. Several pellets were obtained by a radical polymerization process for $24 \mathrm{~h}$ at $60{ }^{\circ} \mathrm{C}$ from a mixture of cluster precursors (from 0.025 to $0.1 \mathrm{wt} \%$ ), methyl methacrylate and AIBN (azobisisobutyronitrile) as initiator (Fig. 5a). Owing to the low solubility of $\left[\left(\operatorname{Re}_{6} \mathrm{Q}_{8}{ }_{8}\right)(t b p)^{\mathrm{a}}{ }_{4}(\mathrm{MA})_{2}{ }_{2}\right]$ in neat MMA, the maximum amount of the cluster in the pellet was limited to $0.1 \mathrm{wt} \%$. Higher cluster content resulting in the loss of pellets transparency. As the $\mathrm{Re}_{6}$ cluster/MMA ratio was kept very low, the processability of the hybrid copolymer appeared very close to that of neat PMMA with an enhanced thermal stability as demonstrated by TGA analysis. Co-polymers emit bright-red phosphorescence (Fig. 5b) upon excitation anywhere in the absorption band of the cluster $(300-550 \mathrm{~nm})$. Luminescence spectrum of copolymers revealed the typical spectra of the cluster core with a broad and structureless band that extended from $600 \mathrm{~nm}$ to more than $950 \mathrm{~nm}$, with the maximum wavelength $\lambda_{\text {em }}$ centered at around $710 \mathrm{~nm}$. Absolute emission quantum yield was measured to be about 0.07. It is worth noting that this value is one of the highest photoluminescence quantum yields reported so far for red-NIR luminescent polymers doped with inorganic compounds and does not degrade after several months of ageing. Encapsulation of clusters in this particular polymeric matrix prevents (or minimize) quenching of photoluminescence by oxygen as it is observed in solution. Beyond the possibility to be shaped in bulk form by usual melting processes of polymers technologies, these hybrid materials are soluble in organic solvents which allows their processing into thin films with techniques used for large surfaces preparation like casting, dip coating, or spin coating. Compare to other 
red photobleaching proof emitters, $\mathrm{Re}_{6}$ cluster are not sensitive to their coordination environment as found for rare earths ions and they do not exhibit toxic behavior like quantum dots.

\section{V.b. Liquid crystals}

Metal-containing liquid crystals, the so-called metallomesogens, combine the unique properties of anisotropic fluids with the specific properties of metals (e.g. geometry of coordination, optic, electronic, magnetic). Clustomesogens associate mesomorphism with the unique properties of metal atom clusters [139, 140]. The added value of clustomesogens, compared to metallomesogens is that their luminescence properties are not influenced by their supramolecular organization and only poorly by their surrounding ligands. This peculiar point is of interest since known properties can be directly imported in the desired hybrid matrices. The development of such a class of nanomaterials should offer great potential in the design of new electricity-to-light energy conversion systems, optically based sensors, and displays. Two approaches have been developed to obtain clustomesogens: a covalent approach and an ionic one.

The covalent approach is based on the covalent anchoring of promesogenic moieties containing organic ligands onto the clusters which leads to hybrid building blocks able of self-assembling. The covalent approach is well developed in the case of molybdenum. Some preliminary results have been reported in the case of $\operatorname{Re}_{6}$ clusters. The strategy was to functionalize $\left[\left(\operatorname{Re}_{6} \mathrm{Q}_{8}{ }_{8}\right)(\mathrm{tbp})_{4}^{\mathrm{a}}(\mathrm{OH})_{2}^{\mathrm{a}}\right]^{0}$ cluster by two gallate where methoxy groups have been replaced by an octyloxy chains. Luminescence experiments $\left(\lambda_{\mathrm{ex}}=450 \mathrm{~nm}\right)$ showed a intense emission spectrum centered at $720 \mathrm{~nm}$. Irradiation at $\lambda_{\mathrm{ex}}=405 \mathrm{~nm}$ of trans-functionalized clusters induced a bright red luminescence. A promising birefringent texture could be observed at $25{ }^{\circ} \mathrm{C}$ by polarised optical microscopy. However, compounds decompose around $250{ }^{\circ} \mathrm{C}$ before reaching the clearing temperature.

The ionic approach is based on the pairing via Coulomb interactions of anionic clusters with promesogenic moieties containing organic cations [61]. Indeed, $\left[\left(\operatorname{Re}_{6} \mathrm{Se}_{8}{ }_{8}\right)(\mathrm{CN})_{6}^{\mathrm{a}}\right]^{\mathrm{n}-}(\mathrm{n}=3,4)$ cluster units were paired with appropriate amphiphilic ammonium cations (Fig. 6). These inorganic units are particularly relevant because, thanks to cyano ligands that prevent any ligands exchange, they are chemically very stable and exhibit a low reversible one electron oxidation potential. The latter enables to switch reversibly from an orange colored form $(n=4, \mathrm{VEC}=24)$ with red-NIR luminescence properties, to a magnetic green colored species $(n=3$, VEC = 23). The oxidation-reduction process can be easily implemented by both electrochemical and chemical oxidations. In this frame $\left(\mathrm{Kat}_{3}{ }_{3}\left[\left(\operatorname{Re}_{6} \mathrm{Se}_{8}{ }_{8}\right)(\mathrm{CN})_{6}{ }_{6}\right]\right.$ and $\left(\mathrm{Kat}_{4}\left[\left(\operatorname{Re}_{6} \mathrm{Se}_{8}{ }_{8}\right)(\mathrm{CN})_{6}^{\mathrm{a}}\right]\right.$ were obtained by pairing $\left[\left(\operatorname{Re}_{6} \operatorname{Se}_{8}{ }_{8}\right)(\mathrm{CN})_{6}^{\mathrm{a}}\right]^{3-}$ and $\left[\left(\operatorname{Re}_{6} \mathrm{Se}_{8}{ }_{8}\right)(\mathrm{CN})_{6}^{\mathrm{a}}\right]^{4-}$ with dialkyldimethylammonium counter cations (denoted as Kat) bearing cyanobiphenyloxy terminated alkyl chains.

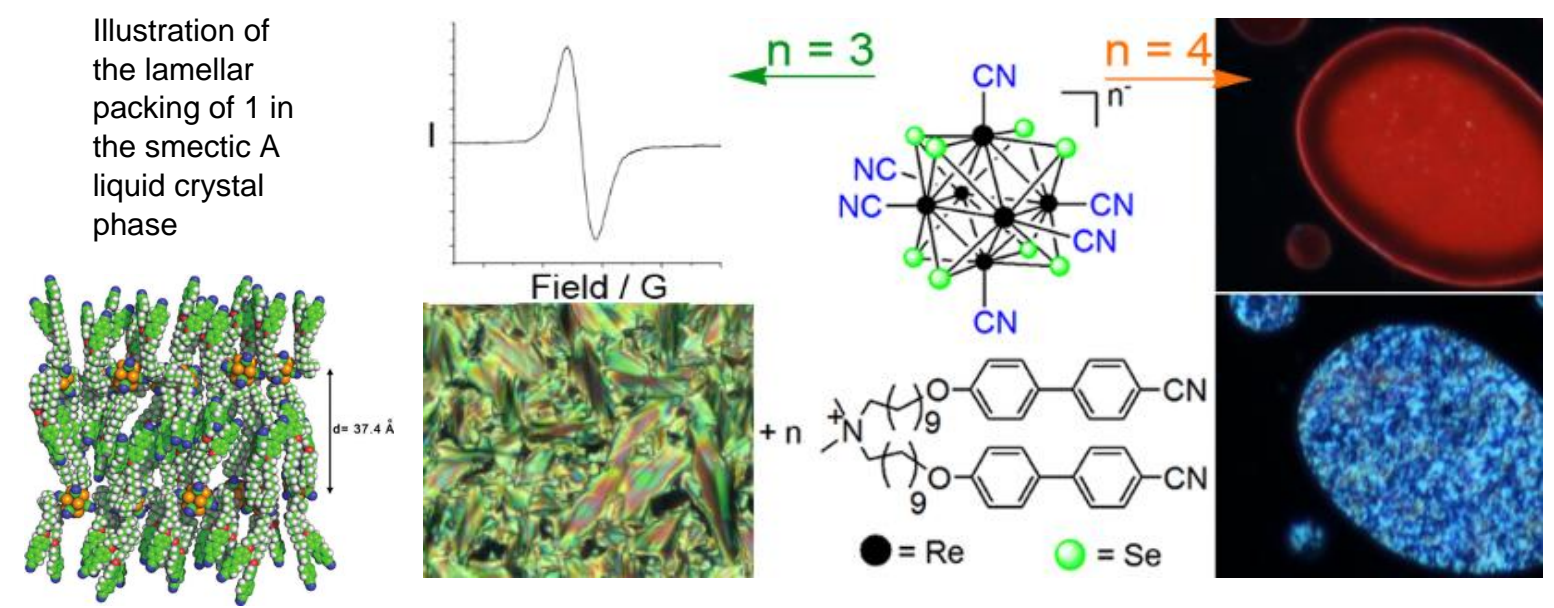

Fig. 6 The pairing of $\left[\left(\operatorname{Re}_{6} \mathrm{Se}_{8}{ }_{8}\right)(\mathrm{CN})^{\mathrm{a}} 6\right]^{3-}$ with Kat leads to the formation of smectic liquid crystal phase with a paramagnetic behavior and the $\left[\left(\operatorname{Re}_{6} \mathrm{Se}_{8}{ }_{8}\right)(\mathrm{CN})^{\mathrm{a}}{ }_{6}\right]^{4-}$ with Kat leads to the formation of diamagnetic luminescent phase with liquid crystal properties. Reprinted from [61] with permission from ACS.

The reaction pairing simply consists in a precipitation by addition of a hot ethanol solution of $\mathrm{KatBr}$ in a water solution of $\left[\left(\operatorname{Re}_{6} \mathrm{Se}_{8}{ }_{8}\right)(\mathrm{CN})_{6}^{\mathrm{a}}\right]^{\mathrm{n}-}$. Both hybrid compounds exhibit a lyotropic behavior with organic solvent such as chloroform: $\left(\mathrm{Kat}_{3}\left[\left(\operatorname{Re}_{6} \mathrm{Se}_{8}^{\mathrm{i}}\right)(\mathrm{CN})_{6}^{\mathrm{a}}\right]\right.$ shows a texture of nematic type containing broad schlieren features 
along with large homeotropic areas, while $\left(\mathrm{Kat}_{4}\left[\left(\operatorname{Re}_{6} \mathrm{Se}_{8}{ }_{8}\right)(\mathrm{CN})_{6}^{\mathrm{a}} 6\right.\right.$ exhibits a marbled texture also of nematic type. From the thermotropic liquid crystal point of view, $\left(\mathrm{Kat}_{4}\right)_{4}\left[\left(\operatorname{Re}_{6} \mathrm{Se}_{8}{ }_{8}{ }_{8}(\mathrm{CN})_{6}^{\mathrm{a}}{ }_{6}\right.\right.$ does not exhibit clear mesomorphic properties but $\left(\mathrm{Kat}_{3}\left[\left(\operatorname{Re}_{6} \mathrm{Se}_{8}{ }_{8}\right)(\mathrm{CN})_{6}^{\mathrm{a}}\right]\right.$ self-organizes smoothly in a layered phase of Smectic A type between $40^{\circ} \mathrm{C}$ and $140^{\circ} \mathrm{C}$. The intrinsic properties of the molecular inorganic cluster are preserved within the mesomorphic material. It is therefore possible to switch reversibly this LC material from a green-colored magnetic form to a bright red-NIR luminescent one. These compounds, because of their low clearing temperature, can be integrated and annealed directly in devices. Yet that the concept of such class of material is demonstrated, the endless range of possibilities offered by organic chemists to design particular mesogenic cations allowing a fine-tuning of the final material mesomorphic behavior, associated with the versatility of the inorganic clusters (charge, functions) obtained via high temperature solid-state synthesis, open new and fascinating perspectives in the design of easy processable functional material containing transition metal clusters.

\section{V.c. Functional surfaces}

One successful strategy to design functional devices consists in the immobilization onto surfaces of nanometerscaled building blocks endowed with specific properties. Many approaches can be developed. Indeed, for optical or catalytic properties and even hydrogen storage, metal atom clusters can be immobilized onto a surface like graphene or incorporated in metal organic frameworks. Photocatalytic properties are thus driven by irradiation and depend on the used wavelength. In order to obtain electrically addressable and switchable functional devices (e.g. optical or magnetic arrays, biochemical sensors with electrical detection, or hybrid junctions for charge storage components), active building blocks must be integrated on to conducting surfaces. Many research work has been devoted to the design of molecular memory cells or junctions consisting in the immobilization of redoxactive molecules (e.g., metal-complexed porphyrins, ferrocene, etc.) including metal atom clusters on conducting surfaces. The strategy that has been developed for the anchoring of $\mathrm{Mo}_{6} \mathrm{X}_{8} \mathrm{~L}_{6}{ }_{6}$ cluster unit on surfaces was based on the synthesis and manipulation of $\left[\left(\mathrm{Mo}_{6} \mathrm{X}_{8}{ }^{\mathrm{i}}\right)\left(\mathrm{CF}_{3} \mathrm{SO}_{3}\right)_{6}{ }_{6}\right]^{2-}$ unstable intermediates. The surface grafting consisted in the reaction of $\left[\left(\mathrm{Mo}_{6} \mathrm{X}_{8}{ }_{8}\right)\left(\mathrm{CF}_{3} \mathrm{SO}_{3}\right)_{6}^{\mathrm{a}}\right]^{2-}$ with a pyridine-terminated alkyl monolayer-modified silicon semiconducting surface which had been previously prepared from an oxide free, hydrogen-terminated silicon $(\mathrm{Si}-\mathrm{H})$. Thanks to the lability of the $\mathrm{CF}_{3} \mathrm{SO}_{3}{ }^{-}$groups, the cluster was immobilized through a strong covalent bond between the cluster and the nitrogen atom from the pyridine unit endcapping the alkyl chain. After the anchoring 1 step, the modified surface was then dipped into neat pyridine in order to replace the remaining $\mathrm{CF}_{3} \mathrm{SO}_{3}{ }^{-}$groups by pyridine rings and obtain a stable surface and not reacting with water vapour. For the immobilization of $\operatorname{Re}_{6}$ clusters and thanks to stability and the reactivity of the $\left[\left(\operatorname{Re}_{6} \mathrm{Q}_{8}{ }_{8}\right)(\operatorname{tbp})_{4}{ }_{4}(\mathrm{OH})^{\mathrm{a}}\right]^{0}$ with carboxylic acids, a more straightforward strategy was developed. Indeed, $\mathrm{Re}_{6}$-functionalized surfaces were obtained by simple acido-basic reaction of $\left[\left(\operatorname{Re}_{6} \mathrm{Q}_{8}{ }^{\mathrm{i}}\right)(\mathrm{tbp})^{\mathrm{a}}{ }_{4}(\mathrm{OH})_{2}{ }_{2}\right]^{0}$ with a Si-H surface modified by an alkyl monolayer terminated by carboxylic groups (Fig. 7). After reaction in refluxing chlorobenzene, carboxylate groups were formed which led to the anchoring of the cluster on the surface through strong covalent $\mathrm{Re}_{6}-\mathrm{O}$ bonds. This simple water elimination reaction enabled the formation of a stable organic chain/cluster interface. This grafting technique greatly simplifies the cluster immobilization procedure as compared with that used previously for $\left[\left(\mathrm{Mo}_{6} \mathrm{X}_{8}^{\mathrm{i}}\right) \mathrm{L}_{6}{ }_{6}\right]$ cluster units. Interestingly, the surface coverage of the metal cluster could be finely controlled by preparing mixed monolayers containing reactive $\mathrm{COOH}$-terminated alkyl chains diluted with inert alkyl chains with a predefined surface chain ratio. Using mixed dodecyl/undecanoic acid monolayers, the surface coverage of $\left[\left(\operatorname{Re}_{6} \mathrm{Q}_{8}{ }^{\mathrm{i}}\right)(\mathrm{tbp})^{\mathrm{a}}{ }_{4}(\mathrm{OH})^{\mathrm{a}}{ }_{2}\right]^{0}$ cluster units could be varied from $1 \times 10^{13}$ to $6 \times 10^{13} \mathrm{~cm}^{-2}$ [141]. Different surface characterization techniques, such as scanning tunneling microscopy (STM, Fig 7), spectroscopic ellipsometry, and quantitative X-ray photoemission spectroscopy (XPS), were used to demonstrate the covalent immobilization of $\operatorname{Re}_{6}$ clusters. Furthermore, the cluster integrity within the monolayer was confirmed by its vibrational Raman signature. Charge transport characteristics were evaluated by measuring the current intensity flowing through the functional monolayer upon the application of a voltage between a soft top contact (mercury droplet) and the underlying silicon surface. The as formed $\mathrm{Hg} /\left(\mathrm{Re}_{6} \mathrm{Se}_{8}{ }^{\mathrm{i}}\right)-\mathrm{OML}-\mathrm{Si}(111)$ molecular junctions $\left(\mathrm{OML}=\right.$ organic chain monolayer) with the highest $\left(\operatorname{Re}_{6} \mathrm{Se}_{8}{ }_{8}\right)$ molecular coverage showed current-voltage $(I-V)$ characteristics different from those observed for classical Schottky diodes. The following three main features were observed: (i) a small rectification factor; (ii) a decrease in the conductance $G(V)$ by more than one decade. The observation of the signature of the metal cluster immobilization in $G(V)$ characteristics required a molecular coverage on the order of $4 \times 10^{13} \mathrm{~cm}^{-2}$ for $\mathrm{Re}_{6}$-cluster-based junctions. 
a

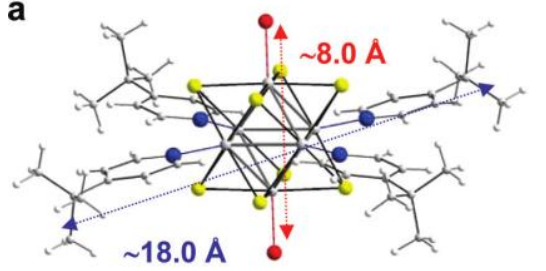

C

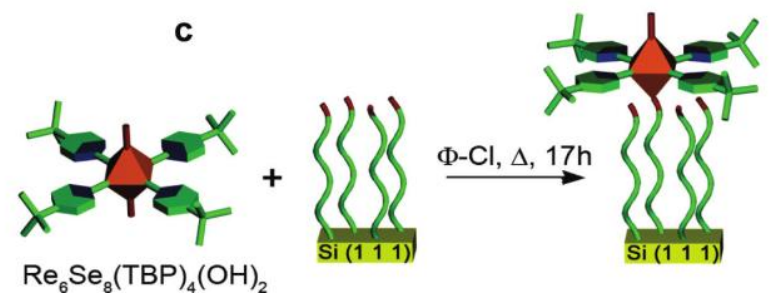

b

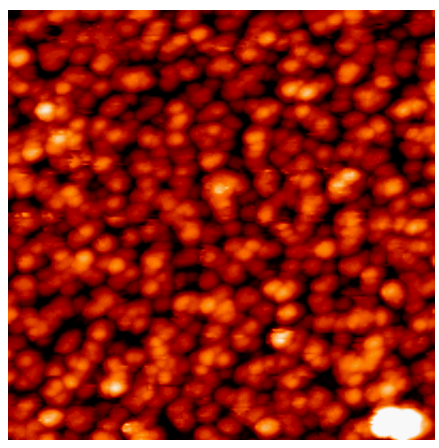

Fig. 7 Left, (a) Representation of the trans $-\left[\left(\operatorname{Re}_{6} \mathrm{Se}^{\mathrm{i}}{ }_{8}\right)(\mathrm{TBP})^{\mathrm{a}}{ }_{4}(\mathrm{OH})_{2} \mathrm{a}_{2}\right]$ cluster unit. Selenium, rhenium from the Re 6 clusters, and nitrogen atoms are represented as yellow, grey, and blue balls, respectively. (b) Representation of the same units according to a different orientation. (c) Schematic representation of the $\left(\operatorname{Re}_{6} \mathrm{Se}_{8}\right)^{2+}$ cluster immobilization on $\mathrm{Si}(111)$ through an acido-basic reaction with carboxylic acid headgroups endcapping an alkyl chain. Right, STM image of a cluster functionalized surface evidencing the homogeneous distribution of clusters onto the surface. Reprinted from [141] with permission from ACS.

Moreover, from scanning tunneling spectroscopy (STS), it has been found that the HOMO-LUMO energy gap increased from roughly $2 \mathrm{eV}$ to $4 \mathrm{eV}$ after the immobilization step. Therefore, this grafting strategy is particular attractive for controlling the electronic properties of the metal cluster-terminated molecular junctions. Moreover, through a judicious choice of functional ligands substituting the immobilized cluster units, it becomes also possible to develop redox-active interfaces endowed with versatile magnetic, luminescent and catalytic properties.

\section{Toward theranostic tools based on silica nanoparticles}

$\left[\left(\operatorname{Re}_{6} \mathrm{Q}_{8}{ }^{\mathrm{i}}\right) \mathrm{L}_{6}^{\mathrm{a}}\right]$ clusters units emit in the red and near-infrared (NIR) regions, which constitute a very interesting emitting window for biotechnology since it corresponds to the window of minimum absorption of tissues [142]. Moreover, because they combine the important properties of perfectly reproducible nanosize, photostability, and NIR emission with other properties like the generation of singlet oxygen and do not show acute toxic effects, $\operatorname{Re}_{6}$ clusters may offer complementary assets to the luminophores nowadays developed for bioimaging and biolabeling technologies. They are mainly based on organic dyes, inorganic quantum dots, or lanthanide based nanocrystals. Several recent results evidence the increasing interest of rhenium atom clusters in theranostic [81, $132,143,144]$. Beyond interesting labelling properties and thanks to the generation of oxygen singlet, the $\operatorname{Re}_{6}$ clusters are relevant candidates for photodynamic therapy. Moreover, it has been demonstrated that the $\left[\left(\operatorname{Re}_{6} \operatorname{Se}_{8}{ }_{8}\right) I_{6}{ }_{6}\right]^{3-}$ cluster anionic units in certain conditions selectively increase tumor cell death, leaving nontumoral cells unaffected. Indeed, $\mathrm{Re}_{6}$ clusters may be useful for cancer diagnostics, localization of tumors, and may enable the observation of tumor regression through phosphorescence [132]. Last but not least, the transport and delivering of $\left[\left(\operatorname{Re}_{6} \mathrm{Q}_{8}{ }_{8}\right)(\mathrm{OH})_{6}^{\mathrm{a}}\right]^{4-}$ cluster units can be achieved by sugar-decorated dendritic nanocarriers and the cellular uptake can be considerably improved by the functionalization with an amphiphilic diblock copolymer [89]. Indeed different systems can be imagined and designed and not only for theranostic. In this frame, the versatility of silica nanoparticles is very relevant for the elaboration of multifunctional systems and in particular nanoparticles. Because they can support very different kind of functional nanoobjects, they found numerous applications in photonics, catalysis or biotechnologies [145, 146]. Beyond their non-toxicity, their surface can be functionalized by molecules of interest in biology [147]. Luminescent cluster-based monodispersed nanoparticles prepared by water in oil microemulsion or Stöber processes have been reported [46, 90, 148-151]. Additional properties have been obtained by the inclusion of maghemite at the core of the nanoparticle or by the growth of gold nanoparticles at the surface of silica $[152,153]$. $\mathrm{Re}_{6}$-cluster based silica nanoparticles have been obtained by embedding cationic phosphine-terminated rhenium chalcogenide clusters 
$\left[\left(\operatorname{Re}_{6} \operatorname{Se}_{8}{ }_{8}\right)\left(\mathrm{Et}_{3} \mathrm{P}\right)_{5}^{\mathrm{a}} \mathrm{I}^{\mathrm{a}}\right] \mathrm{I}, \quad\left[\left(\operatorname{Re}_{6} \mathrm{~S}_{8}{ }_{8}\right)\left(\mathrm{Et}_{3} \mathrm{P}\right)_{5}^{\mathrm{a}} \mathrm{Br}^{\mathrm{a}}\right] \mathrm{Br}, \quad\left[\left(\operatorname{Re}_{6} \mathrm{Se}_{8}{ }_{8}\right)\left(\mathrm{Bu}_{3} \mathrm{P}\right)^{\mathrm{a}}{ }_{5} \mathrm{I}^{\mathrm{a}}\right] \mathrm{I}$, and $\left[\left(\operatorname{Re}_{6} \mathrm{~S}_{8}{ }_{8}\right)\left(\mathrm{Bu}_{3} \mathrm{P}\right)_{5}^{\mathrm{a}} \mathrm{Br}^{\mathrm{a}}\right] \mathrm{Br}$ in silica nanospheres in a one-pot, base-catalyzed hydrolysis in acetonitrile [121]. On the basis of their ability to generate singlet oxygen, they are potential candidates for photodynamic therapy and for other applications. In such nanoparticles, it appears that interactions between cationic cluster units (i.e. $\left[\left(\operatorname{Re}_{6} \operatorname{Se}_{8}{ }_{8}\right)\left(\operatorname{Et}_{3} \mathrm{P}\right)^{\mathrm{a}} \mathrm{I}^{\mathrm{a}}\right]^{+}$, $\left[\left(\operatorname{Re}_{6} \mathrm{~S}_{8}^{\mathrm{i}}\right)\left(\mathrm{Et}_{3} \mathrm{P}\right)^{\mathrm{a}}{ }_{5} \mathrm{Br}^{\mathrm{a}}\right]^{+},\left[\left(\operatorname{Re}_{6} \mathrm{Se}_{8}^{\mathrm{i}}\right)\left(\mathrm{Bu}_{3} \mathrm{P}\right)_{5}^{\mathrm{a}} \mathrm{I}^{\mathrm{a}}\right]^{+}$, and $\left.\left[\left(\mathrm{Re}_{6} \mathrm{~S}_{8}{ }_{8}\right)\left(\mathrm{Bu}_{3} \mathrm{P}\right)_{5}^{\mathrm{a}} \mathrm{Br}^{\mathrm{a}}\right]^{+}\right)$and the anionic deprotonated silanol groups occur. Another strategy is the direct synthesis of $\mathrm{Re}_{6}$ cluster-silica nanoparticles directly from water soluble precursors: $\mathrm{K}_{4}\left[\left(\operatorname{Re}_{6} \mathrm{Q}_{8}^{\mathrm{i}}\right)(\mathrm{OH})_{6}^{\mathrm{a}}\right](\mathrm{Q}=\mathrm{S}$ or $\mathrm{Se}), \mathrm{Cs}_{4}\left[\left(\mathrm{Re}_{6} \mathrm{~S}_{8}{ }_{8}\right) \mathrm{Br}_{6}^{\mathrm{a}}{ }_{6}\right.$, and $\mathrm{Cs}_{1.68} \mathrm{~K}_{2.32}\left[\left(\operatorname{Re}_{6} \mathrm{~S}_{8}{ }_{8}\right)(\mathrm{CN})^{\mathrm{a}}{ }_{4}(\mathrm{OH})^{\mathrm{a}}{ }_{2}\right]$ [90]. Indeed, the $\mathrm{A}_{4}\left[\left(\operatorname{Re}_{6} \mathrm{Q}_{8}{ }_{8}\right) \mathrm{L}_{6}^{\mathrm{a}}\right] @ \mathrm{SiO}_{2}$ nanoparticles were prepared through a microemulsion process adapted from a previously reported synthesis for the encapsulation of hexamolybdenum clusters in silica nanoparticles (Fig. 8).

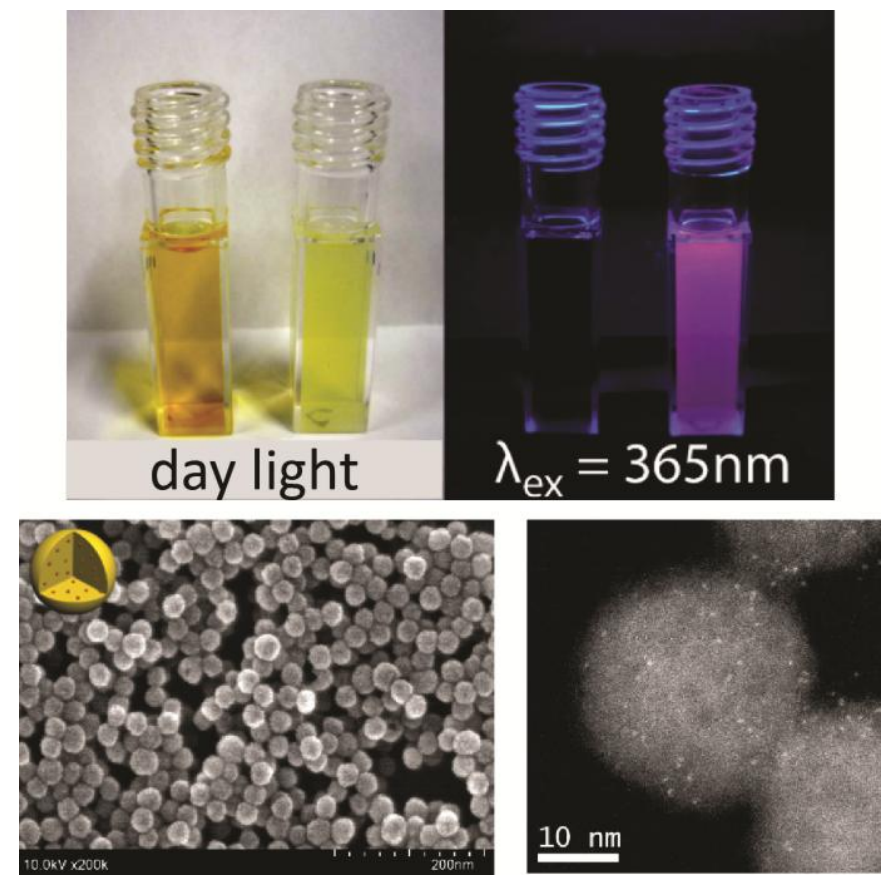

Fig. 8 Top, aqueous solution of $\left[\left(\mathrm{Re}_{6} \mathrm{~S}_{8}{ }_{8}\right)(\mathrm{OH})^{\mathrm{a}} 6\right]^{4-}$ clusters (a) before and (b) after embedding in silica nanoparticles, under daylight (left picture) and under UV irradiation at $365 \mathrm{~nm}$ (right picture). Down-left, FE-SEM pictures of (a) $\mathrm{K}_{4}\left[\left(\mathrm{Re}_{6} \mathrm{~S}_{8}{ }^{\mathrm{i}}\right)(\mathrm{OH})_{6}^{\mathrm{a}}\right] @ \mathrm{SiO}_{2}$ (inset: schematic representation of dispersed clusters inside the nanoparticles). Down-right, ADFSTEM pictures of $\mathrm{K}_{4}\left[\left(\mathrm{Re}_{6} \mathrm{~S}_{8}{ }_{8}\right)(\mathrm{OH})_{6}^{\mathrm{a}}{ }_{6}\right] \mathrm{SiO}_{2}$ nanoparticles with discrete cluster units (bright spots). Reprinted from [90] with permission from ACS.

To generate the microemulsion, heptane (oil phase) was first mixed with Brij30 (surfactant), and then an aqueous ammonia solution and an aqueous cluster sol were slowly added to the mixture. The aqueous cluster sol was obtained simply by solubilization of the cluster precursor in water. Once the microemulsion became a clear, stable solution, the silica precursor (tetraethoxysilane, TEOS) was added for the synthesis of the silica shell that occurred directly inside the aqueous nanodroplets already containing the cluster units. After 3 days, the microemulsion was destabilized with ethanol and the nanoparticles were recovered after washing. Resulting nanoparticles could be either redispersed in solution (water or ethanol) or dried in ambient air. The $\mathrm{A}_{4}\left[\left(\mathrm{Re}_{6} \mathrm{Q}_{8}{ }_{8}\right) \mathrm{L}_{6}^{\mathrm{a}}{ }_{6} @ \mathrm{SiO}_{2}\right.$ nanoparticles showed that they all exhibited a perfectly spherical, monodisperse morphology with an average diameter of $30 \mathrm{~nm}$ for the synthesis conditions. The encapsulation of the $\left[\left(\mathrm{Re}_{6} \mathrm{Q}_{8}{ }_{8}\right)(\mathrm{OH})_{6}^{\mathrm{a}}\right]^{4-}(\mathrm{Q}=\mathrm{Se}$ or $\mathrm{S})$ and $\left[\left(\mathrm{Re}_{6} \mathrm{~S}_{8}{ }_{8}\right)(\mathrm{CN})_{4}^{\mathrm{a}}(\mathrm{OH})_{2}^{\mathrm{a}}\right]^{4-}$ cluster units in the silica matrix resulted in a slight shift of the emission maxima after embedding, but the shape of the emission spectrum remained unchanged (Figure 5a-c). The emission maximum shifting, ranging from 10 to $20 \mathrm{~nm}$, to higher wavelengths between solidstate precursors and the nanoparticles must be due to some perturbations of the molecular orbital diagram of $\left[\left(\operatorname{Re}_{6} \mathrm{Q}_{8}{ }_{8}\right) \mathrm{L}_{6}^{\mathrm{a}}\right]^{4-}$ units after embedding. One could suspect a slight decrease in the energy gap between excited and fundamental states. Note that the use of $\mathrm{K}_{4}\left[\left(\mathrm{Re}_{6} \mathrm{Q}_{8}{ }_{8}\right)(\mathrm{OH})_{6}^{\mathrm{a}}\right](\mathrm{Q}=\mathrm{S}$ or $\mathrm{Se})$ or $\mathrm{Cs}_{4}\left[\left(\mathrm{Re}_{6} \mathrm{~S}_{8}{ }^{\mathrm{i}}\right) \mathrm{Br}_{6}{ }_{6}\right]$ as starting precursor leads to $\mathrm{K}_{4}\left[\left(\mathrm{Re}_{6} \mathrm{Q}_{8}^{\mathrm{i}}\right)(\mathrm{OH})_{6}^{\mathrm{a}}\right] @ \mathrm{SiO}_{2}$ and $\mathrm{Cs}_{4}\left[\left(\mathrm{Re}_{6} \mathrm{Q}_{8}^{\mathrm{i}}\right)(\mathrm{OH})_{6}^{\mathrm{a}}\right]{ }_{6} @ \mathrm{SiO}_{2}$ meaning that during the reaction, apical bromine atoms are substituted by $\mathrm{OH}$ groups. By analogy with the work on the encapsulation of $\left[\left(\mathrm{Mo}_{6} \mathrm{Br}_{8}{ }_{8}\right)_{\mathrm{Br}_{6}}{ }_{6}\right]^{2-}$ units in silica where the substitution of bromine apical bromine by hydroxo groups occur, two kinds of interactions occur with silica. The first one is an interaction by the formation of hydrogen bonds 
between $\mathrm{OH}$ of the cluster and the silanol groups of the silica and the second one is an interaction by covalent bond between cluster units and the silica matrix. These $\operatorname{Re}_{6}$ cluster-based nanoparticles have the luminescent properties of the cluster precursor. It means that the luminescent properties of the cluster from the core of the nanoparticles are not quenched by oxygen. Moreover, since the luminescence intensity of nanoparticles decreases until a minimum in the presence of oxygen, it means that the silica is porous and clusters near to the surface of silica are quenched by oxygen and thus generate singlet oxygen. Based on these results and the fact that $\operatorname{Re}_{6}$ clusters are not significantly toxic and that they exhibit antitumoral properties, $\operatorname{Re}_{6}$ cluster based silica nanoparticles should be relevant tools for theranostic applications.

\section{Conclusions}

Fifty years after the definition of the term "metal atom cluster" by F. A. Cotton, this review showed the step by step evolution of the rhenium metal atom cluster chemistry toward an interdisciplinary field of research from the synthesis of cluster by solid state chemistry, their functionalization by solution chemistry or in organic melts to their use as building block for the elaboration of molecular assemblies, extended molecular frameworks and nanomaterials. It showed in particular all the different strategies that have been used in order to take advantage of their unique properties originating from metal-metal bonding to obtain nanostructured and processable functional materials. We thus believe that the three first steps of the development of metal atom cluster chemistry and in particular the third step dealing with functional materials described in this review will be followed by a fourth step that should be focused on the development and commercialization of devices and nanomaterials built up from transition metal atom clusters in the fields of lighting, display, green chemistry or health. It should not only concern rhenium chemistry but all nanosized transition metal atom clusters.

\section{Acknowledgement.}

We thank the France-Russia programs PICS (2011-2013 N5822) and International Associate Laboratory (20142017) as well as the IDEMAT chemistry project in the frame of the Franc Siberian Center of Training and Research. We acknowledge A. Perrin, C. Perrin and V. E. Fedorov for helpful discussions. We are grateful to T. Aubert, M. A. Shestopalov, A. Y. Ledneva, O. A. Efremova and F. Dorson who made a part of their PhD work on this topic of research. 


\section{References}

1. J. C. Sheldon (1962). J. Chem. Soc., 410.

2. R. E. McCarley, and T. M. Brown (1964). Inorg. Chem. 3, 1232.

3. P. J. Kuhn, and R. E. McCarley (1965). Inorg. Chem. 4, 1482.

4. P. B. Fleming, L. A. Mueller, and R. E. McCarley (1967). Inorg. Chem. 6, 1.

5. R. D. Hogue, and R. E. McCarley (1970). Inorg. Chem. 9, 1354.

6. $\quad$ S. Chen, and W. R. Robinson (1978). J. Chem. Soc., Chem. Commun., 879.

7. A. Perrin, M. Sergent, and O. Fischer (1978). Mater. Res. Bull. 13, 259.

8. M. Spangenberg, and W. Bronger (1978). Angew. Chem. 90, 382.

9. R. Chevrel, M. Sergent, and J. Prigent (1971). J. Solid State Chem. 3, 515.

10. T. Zhou, B. Lenoir, M. Colin, A. Dauscher, R. A. R. Al Orabi, P. Gougeon, M. Potel, and E. Guilmeau (2011). Appl. Phys. Lett. 98, 162106.

11. J. M. Tarascon, F. J. Disalvo, D. W. Murphy, G. W. Hull, E. A. Rietman, and J. V. Waszczak (1984). J. Solid State Chem. 54, 204.

12. L. Cario, C. Vaju, B. Corraze, V. Guiot, and E. Janod (2010). Adv. Mater. 22, 5193.

13. G. Prabusankar, Y. Molard, S. Cordier, S. Golhen, Y. Le Gal, C. Perrin, L. Ouahab, S. Kahlal, and J. F. Halet (2009). Eur. J. Inorg. Chem., 2153.

14. L. G. Beauvais, M. P. Shores, and J. R. Long (2000). J. Am. Chem. Soc. 122, 2763.

15. M. V. Bennett, M. P. Shores, L. G. Beauvais, and J. R. Long (2000). J. Am. Chem. Soc. $122,6664$.

16. V. E. Fedorov, N. G. Naumov, Y. V. Mironov, A. V. Virovets, S. B. Artemkina, K. A. Brylev, S. S. Yarovoi, O. A. Efremova, and U. H. Peak (2002). J. Struct. Chem. 43, 669.

17. K. A. Brylev, Y. V. Mironov, N. G. Naumov, V. E. Fedorov, and J. A. Ibers (2004). Inorg. Chem. 43, 4833.

18. Y. V. Mironov, N. G. Naumov, K. A. Brylev, O. A. Efremova, V. E. Fedorov, and K. Hegetschweiler (2004). Angew. Chem., Int. Ed. 43, 1297.

19. K. A. Brylev, G. Pilet, N. G. Naumov, A. Perrin, and V. E. Fedorov (2005). Eur. J. Inorg. Chem., 461.

20. S. Ababou-Girard, S. Cordier, B. Fabre, Y. Molard, and C. Perrin (2007). ChemPhysChem 8, 2086.

21. B. Fabre, S. Cordier, Y. Molard, C. Perrin, S. Ababou-Girard, and C. Godet (2009). J. Phys. Chem. C 113, 17437.

22. Z. Zheng, and X. Y. Tu (2009). CrystEngComm 11, 707.

23. H. D. Selby, B. K. Roland, J. R. Cole, and Z. Zheng (2004). Macromol. Symp. 209, 23.

24. B. K. Roland, H. D. Selby, J. R. Cole, and Z. Zheng (2003). Dalton Trans., 4307.

25. H. D. Selby, P. Orto, M. D. Carducci, and Z. Zheng (2002). Inorg. Chem. 41, 6175.

26. J. H. Golden, H. B. Deng, F. J. Disalvo, J. M. J. Frechet, and P. M. Thompson (1995). Science $268,1463$.

27. S. Cordier, F. Dorson, F. Grasset, Y. Molard, B. Fabre, H. Haneda, T. Sasaki, M. Mortier, S. AbabouGirard, and C. Perrin (2009). J. Cluster Sci. 20, 9.

28. P. B. Fleming, and R. E. McCarley (1970). Inorg. Chem. 9, 1347.

29. H. Imoto, S. Hayakawa, N. Morita, and T. Saito (1990). Inorg. Chem. 29, 2007.

30. R. Quigley, P. A. Barnard, C. L. Hussey, and K. R. Seddon (1992). Inorg. Chem. 31, 1255.

31. N. G. Naumov, S. Cordier, and C. Perrin (2002). Angew. Chem., Int. Ed. 41, 3002.

32. M. Ebihara, K. Toriumi, and K. Saito (1988). Inorg. Chem. 27, 13.

33. S. G. Kozlova, S. P. Gabuda, K. A. Brylev, Y. V. Mironov, and V. E. Fedorov (2004). Russ. Chem. Bull. 53, 1661.

34. S. G. Kozlova, S. P. Gabuda, K. A. Brylev, Y. V. Mironov, and V. E. Fedorov (2004). J. Phys. Chem. A 108, 10565 .

35. A. W. Maverick, J. S. Najdzionek, D. Mackenzie, D. G. Nocera, and H. B. Gray (1983). J. Am. Chem. Soc. 105, 1878.

36. J. R. Long, L. S. McCarty, and R. H. Holm (1996). J. Am. Chem. Soc. 118, 4603.

37. T. Yoshimura, K. Umakoshi, Y. Sasaki, and A. G. Sykes (1999). Inorg. Chem. 38, 5557.

38. T. G. Gray, C. M. Rudzinski, E. E. Meyer, R. H. Holm, and D. G. Nocera (2003). J. Am. Chem. Soc. 125, 4755.

39. T. Yoshimura, S. Ishizaka, K. Umakoshi, Y. Sasaki, H.-B. Kim, and N. Kitamura (1999). Chem. Lett., 697.

40. T. Yoshimura, S. Ishizaka, Y. Sasaki, H.-B. Kim, N. Kitamura, N. G. Naumov, M. N. Sokolov, and V. E. Fedorov (1999). Chem. Lett., 1121.

41. F. Dorson, Y. Molard, S. Cordier, B. Fabre, O. Efremova, D. Rondeau, Y. Mironov, V. Circu, N. Naumov, and C. Perrin (2009). Dalton Trans., 1297.

42. K. A. Brylev, Y. V. Mironov, S. G. Kozlova, V. E. Fedorov, S.-J. Kim, H.-J. Pietzsch, H. Stephan, A. Ito, S. Ishizaka, and N. Kitamura (2009). Inorg. Chem. 48, 2309. 
43. M. A. Shestopalov, S. Cordier, O. Hernandez, Y. Molard, C. Perrin, A. Perrin, V. E. Fedorov, and Y. V. Mironov (2009). Inorg. Chem. 48, 1482.

44. T. Yoshimura, C. Suo, K. Tsuge, S. Ishizaka, K. Nozaki, Y. Sasaki, N. Kitamura, and A. Shinohara (2010). Inorg. Chem. 49, 531.

45. M. N. Sokolov, M. A. Mihailov, E. V. Peresypkina, K. A. Brylev, N. Kitamura, and V. P. Fedin (2011). Dalton Trans. 40, 6375.

46. K. Kirakci, P. Kubat, M. Dusek, K. Fejfarova, V. Sicha, J. Mosinger, and K. Lang (2012). Eur. J. Inorg. Chem., 3107.

47. M. N. Sokolov, M. A. Mikhailov, K. A. Brylev, A. V. Virovets, C. Vicent, N. B. Kompankov, N. Kitamura, and V. P. Fedin (2013). Inorg. Chem. 52, 12477.

48. A. Gandubert, K. A. Brylev, T. T. Nguyen, N. G. Naumov, N. Kitamura, Y. Molard, R. Gautier, and S. Cordier (2013). Z. Anorg. Allg. Chem. 639, 1756.

49. A. Y. Ledneva, K. A. Brylev, A. I. Smolentsev, Y. V. Mironov, Y. Molard, S. Cordier, N. Kitamura, and N. G. Naumov (2014). Polyhedron 67, 351.

50. R. E. McCarley, B. G. Hughes, F. A. Cotton, and R. Zimmerman (1965). Inorg. Chem. 4, 1491.

51. J. G. Converse, and R. E. McCarley (1970). Inorg. Chem. 9, 1361.

52. D. D. Klendworth, and R. A. Walton (1981). Inorg. Chem. 20, 1151.

53. D. G. Nocera, and H. B. Gray (1984). J. Am. Chem. Soc. 106, 824.

54. T. C. Zietlow, D. G. Nocera, and H. B. Gray (1986). Inorg. Chem. 25, 1351.

55. C. Guilbaud, A. Deluzet, B. Domercq, P. Molinie, C. Coulon, K. Boubekeur, and P. Batail (1999). Chem. Commun., 1867.

56. Y. V. Mironov, A. V. Virovets, N. G. Naumov, V. N. Ikorskii, and V. E. Fedorov (2000). Chem. Eur. J. 6, 1361.

57. S. Cordier, N. G. Naumov, D. Salloum, F. Paul, and C. Perrin (2004). Inorg. Chem. 43, 219.

58. K. Kirakci, S. Cordier, O. Hernandez, T. Roisnel, F. Paul, and C. Perrin (2005). J. Solid State Chem. 178, 3117.

59. K. Kirakci, S. Cordier, A. Shames, B. Fontaine, O. Hernandez, E. Furet, J. F. Halet, R. Gautier, and C. Perrin (2007). Chem. Eur. J. 13, 9608.

60. S. Tragl, M. Strobele, J. Glaser, C. Vicent, R. Llusar, and H. J. Meyer (2009). Inorg. Chem. 48, 3825.

61. Y. Molard, A. Ledneva, M. Amela-Cortes, V. Circu, N. G. Naumov, C. Meriadec, F. Artzner, and S. Cordier (2011). Chem. Mater. 23, 5122.

62. K. Kirakci, P. Kubat, J. Langmaier, T. Polivka, M. Fuciman, K. Fejfarova, and K. Lang (2013). Dalton Trans. 42, 7224.

63. F. Stollmaier, and A. Simon (1985). Inorg. Chem. 24, 168.

64. N. Prokopuk, C. S. Weinert, V. O. Kennedy, D. P. Siska, H. J. Jeon, C. L. Stern, and D. F. Shriver (2000). Inorg. Chim. Acta 300, 951.

65. J. C. P. Gabriel, K. Boubekeur, S. Uriel, and P. Batail (2001). Chem. Rev. 101, 2037.

66. H. D. Selby, B. K. Roland, and Z. Zheng (2003). Acc. Chem. Res. 36, 933.

67. N. G. Naumov, S. Cordier, and C. Perrin (2004). Chem. Commun., 1126.

68. A. Flemming, and M. Kockerling (2009). Angew. Chem., Int. Ed. 48, 2605.

69. O. Reckeweg, and H. J. Meyer (1995). Z Naturforsch B 50, 1377.

70. N. Prokopuk, V. O. Kennedy, C. L. Stern, and D. F. Shriver (1998). Inorg. Chem. 37, 5001.

71. O. Reckeweg, H. J. Meyer, and A. Simon (2002). Z. Anorg. Allg. Chem. 628, 920.

72. N. G. Naumov, S. Cordier, F. Gulo, T. Roisnel, V. E. Fedorov, and C. Perrin (2003). Inorg. Chim. Acta 350, 503.

73. B. B. Yan, H. J. Zhou, and A. Lachgar (2003). Inorg. Chem. 42, 8818.

74. J. J. Zhang, and A. Lachgar (2007). J. Am. Chem. Soc. 129, 250.

75. N. Prokopuk, and D. F. Shriver (1999). Chem. Mater. 11, 1230.

76. G. Schneider, and Y. Lindqvist (1994). Acta Crystallogr D 50, 186.

77. T. Neuefeind, A. Bergner, F. Schneider, A. Messerschmidt, and J. Knablein (1997). Biol. Chem. $378,219$.

78. P. Kumar, S. Kumar, S. Cordier, S. Paofai, R. Boukherroub, and S. L. Jain (2014). RSC Advances 4, 10420.

79. A. Barras, S. Cordier, and R. Boukherroub (2012). Appl. Catal. B 123, 1.

80. J. A. Jackson, M. D. Newsham, C. Worsham, and D. G. Nocera (1996). Chem. Mater. 8, 558.

81. L. Gao, M. A. Peay, and T. G. Gray (2010). Chem. Mater. 22, 6240.

82. S. Cordier, K. Kirakci, D. Mery, C. Perrin, and D. Astruc (2006). Inorg. Chim. Acta 359, 1705.

83. D. Mery, C. Ornelas, M. C. Daniel, J. Ruiz, J. Rodrigues, D. Astruc, S. Cordier, K. Kirakci, and C. Perrin (2005). C. R. Chim. 8, 1789.

84. D. Mery, L. Plault, S. Nlate, D. Astruc, S. Cordier, K. Kirakci, and C. Perrin (2005). Z. Anorg. Allg. Chem. 631, 2746. 
85. P. Batail, L. Ouahab, A. Penicaud, C. Lenoir, and A. Perrin (1987). C. R. l'Academie. Sci., Ser. II 304, 1111.

86. L. F. Szczepura, D. L. Cedeno, D. B. Johnson, R. McDonald, S. A. Knott, K. M. Jeans, and J. L. Durham (2010). Inorg. Chem. 49, 11386.

87. J. L. Durham, J. N. Tirado, S. A. Knott, M. K. Oh, R. McDonald, and L. F. Szczepura (2012). Inorg. Chem. 51, 7825 .

88. Y. Molard, F. Dorson, K. A. Brylev, M. A. Shestopalov, Y. Le Gal, S. Cordier, Y. V. Mironov, N. Kitamura, and C. Perrin (2010). Chem. Eur. J. 16, 5613.

89. N. Kitamura, Y. Ueda, S. Ishizaka, K. Yamada, M. Aniya, and Y. Sasaki (2005). Inorg. Chem. 44, 6308.

90. T. Aubert, A. Y. Ledneva, F. Grasset, K. Kimoto, N. G. Naumov, Y. Molard, N. Saito, H. Haneda, and S. Cordier (2010). Langmuir 26, 18512.

91. R. Y. Wang, and Z. Zheng (1999). J. Am. Chem. Soc. 121, 3549.

92. X. Y. Tu, G. S. Nichol, P. Keng, J. Pyun, and Z. Zheng (2012). Macromolecules 45, 2614.

93. Y. V. Mironov, J. A. Cody, T. E. Albrecht-Schmitt, and J. A. Ibers (1997). J. Am. Chem. Soc. 119, 493.

94. M. W. Willer, J. R. Long, C. C. McLauchlan, and R. H. Holm (1998). Inorg. Chem. 37, 328.

95. M. P. Shores, L. G. Beauvais, and J. R. Long (1999). J. Am. Chem. Soc. 121, 775.

96. Z. Zheng, T. G. Gray, and R. H. Holm (1999). Inorg. Chem. 38, 4888.

97. S. S. Yarovoi, Y. V. Mironov, S. F. Solodovnikov, D. Y. Naumov, N. K. Moroz, S. G. Kozlova, A. Simon, and V. E. Fedorov (2005). Chem. Commun., 719.

98. Y. V. Mironov, V. E. Fedorov, C. C. McLauchlan, and J. A. Ibers (2000). Inorg. Chem. 39, 1809.

99. N. G. Naumov, S.-J. Kim, A. V. Virovets, Y. V. Mironov, and V. E. Fedorov (2006). Bull. Kor. Chem. Soc. 27, 635 .

100. Y. V. Mironov, S. S. Yarovoi, D. Y. Naumov, A. Simon, and V. E. Fedorov (2007). Inorg. Chim. Acta 360, 2953.

101. T. Yoshimura, K. Umakoshi, Y. Sasaki, S. Ishizaka, H.-B. Kim, and N. Kitamura (2000). Inorg. Chem. 39, 1765.

102. T. Yoshimura, S. Ishizaka, T. Kashiwa, A. Ito, E. Sakuda, A. Shinohara, and N. Kitamura (2011). Inorg. Chem. 50, 9918.

103. Z. Zheng, J. R. Long, and R. H. Holm (1997). J. Am. Chem. Soc. 119, 2163.

104. R. Arratia-Perez, and L. Hernandez-Acevedo (1999). J. Chem. Phys. 111, 168.

105. R. Arratia-Perez, and L. Hernandez-Acevedo (1999). J. Chem. Phys. 110, 2529.

106. L. Alvarez-Thon, L. Hernandez-Acevedo, and R. Arratia-Perez (2001). J. Chem. Phys. 115, 726.

107. H. Honda, T. Noro, K. Tanaka, and E. Miyoshi (2001). J. Chem. Phys. 114, 10791.

108. L. E. Roy, and T. Hughbanks (2006). Inorg. Chem. 45, 8273.

109. A. Slougui, Y. V. Mironov, A. Perrin, and V. E. Fedorov (1995). Croat. Chem. Acta $68,885$.

110. N. G. Naumov, A. V. Virovets, N. V. Podberezskaya, and V. E. Fedorov (1997). J. Struct. Chem. $38,857$.

111. L. G. Beauvais, M. P. Shores, and J. R. Long (1998). Chem. Mater. 10, 3783.

112. H. Imoto, N. G. Naumov, A. V. Virovets, T. Saito, and V. E. Fedorov (1998). J. Struct. Chem. 39, 720.

113. T. Yoshimura, Z.-N. Chen, A. Itasaka, M. Abe, Y. Sasaki, S. Ishizaka, N. Kitamura, S. S. Yarovoi, S. F. Solodovnikov, and V. E. Fedorov (2003). Inorg. Chem. 42, 4857.

114. G. Pilet, S. Cordier, S. Golhen, C. Perrin, L. Ouahab, and A. Perrin (2003). Solid State Sci. $5,1263$.

115. S. S. Yarovoi, Y. V. Mironov, D. Y. Naumov, Y. V. Gatilov, S. G. Kozlova, S.-J. Kim, and V. E. Fedorov (2005). Eur. J. Inorg. Chem., 3945.

116. K. A. Brylev, Y. V. Mironov, S.-J. Kim, and V. E. Fedorov (2007). J. Struct. Chem. 48, 1118.

117. K. A. Brylev, Y. V. Mironov, S. S. Yarovoi, N. G. Naumov, V. E. Fedorov, S.-J. Kim, N. Kitamura, Y. Kuwahara, K. Yamada, S. Ishizaka, and Y. Sasaki (2007). Inorg. Chem. 46, 7414.

118. N. G. Naumov, A. Y. Ledneva, S.-J. Kim, and V. E. Fedorov (2009). J. Cluster Sci. $20,225$.

119. Y. V. Mironov, K. A. Brylev, S.-J. Kim, S. G. Kozlova, N. Kitamura, and V. E. Fedorov (2011). Inorg. Chim. Acta 370, 363.

120. K. A. Brylev (2013). J. Struct. Chem. 54, 196.

121. K. A. Brylev, Y. V. Mironov, V. E. Fedorov, S.-J. Kim, H.-J. Pietzsch, H. Stephan, A. Ito, and N. Kitamura (2010). Inorg. Chim. Acta 363, 2686.

122. N. G. Naumov, A. V. Virovets, Y. I. Mironov, S. B. Artemkina, and V. E. Fedorov (1999). Ukr. Khim. Zh. 65, 21 .

123. J. R. Long, A. S. Williamson, and R. H. Holm (1995). Angew. Chem., Int. Ed. 34, 226.

124. V. P. Fedin, A. A. Virovets, and A. G. Sykes (1998). Inorg. Chim. Acta 271, 228.

125. A. Slougui, S. Ferron, A. Perrin, and M. Sergent (1996). Eur. J. Solid. State Inorg. Chem. 33, 1001.

126. Z. Zheng, and R. H. Holm (1997). Inorg. Chem. 36, 5173.

127. T. G. Gray, C. M. Rudzinski, D. G. Nocera, and R. H. Holm (1999). Inorg. Chem. 38, 5932. 
128. Z.-N. Chen, T. Yoshimura, M. Abe, K. Tsuge, Y. Sasaki, S. Ishizaka, H.-B. Kim, and N. Kitamura (2001). Chem. Eur. J. 7, 4447.

129. M. A. Shestopalov, Y. V. Mironov, K. A. Brylev, S. G. Kozlova, V. E. Fedorov, H. Spies, H.-J. Pietzsch, H. Stephan, G. Geipel, and G. Bernhard (2007). J. Am. Chem. Soc. 129, 3714.

130. T. G. Gray, C. M. Rudzinski, E. E. Meyer, and D. G. Nocera (2004). J. Phys. Chem. A 108, 3238.

131. T. G. Gray (2009). Chem. Eur. J. 15, 2581.

132. S.-J. Choi, K. A. Brylev, J.-Z. Xu, Y. V. Mironov, V. E. Fedorov, Y. S. Sohn, S.-J. Kim, and J.-H. Choy (2008). J. Inorg. Biochem. 102, 1991.

133. Y. V. Mironov, M. A. Shestopalov, K. A. Brylev, S. S. Yarovoi, G. V. Romanenko, V. E. Fedorov, H. Spies, H.-J. Pietzsch, H. Stephan, G. Geipel, G. Bernhard, and W. Kraus (2005). Eur. J. Inorg. Chem., 657.

134. Y. V. Mironov, K. A. Brylev, M. A. Shestopalov, S. S. Yarovoi, V. E. Fedorov, H. Spies, H.-J. Pietzsch, H. Stephan, G. Geipel, G. Bernhard, and W. Kraus (2006). Inorg. Chim. Acta 359, 1129.

135. M. A. Shestopalov, Y. V. Mironov, K. A. Brylev, and V. E. Fedorov (2008). Russ. Chem. Bull. 57, 1644.

136. M. A. Shestopalov, A. A. Ivanov, A. I. Smolentsev, and Y. V. Mironov (2014). J. Struct. Chem. 55, 139.

137. Y. Molard, C. Labbe, J. Cardin, and S. Cordier (2013). Adv. Funct. Mater. 23, 4821.

138. B. K. Roland, W. H. Flora, M. D. Carducci, N. R. Armstrong, and Z. Zheng (2003). J. Cluster Sci. 14,

449.

139. Y. Molard, F. Dorson, V. Circu, T. Roisnel, F. Artzner, and S. Cordier (2010). Angew. Chem., Int. Ed. 49, 3351.

140. A. S. Mocanu, M. Amela-Cortes, Y. Molard, V. Circu, and S. Cordier (2011). Chem. Commun. 47, 2056.

141. S. Cordier, B. Fabre, Y. Molard, A. B. Fadjie-Djomkam, N. Tournerie, A. Ledneva, N. G. Naumov, A. Moreac, P. Turban, S. Tricot, S. Ababou-Girard, and C. Godet (2010). J. Phys. Chem. C 114, 18622.

142. R. Weissleder (2001). Nat. Biotechnol. 19, 316.

143. M. Kubeil, H. Stephan, H.-J. Pietzsch, G. Geipel, D. Appelhans, B. Voit, J. Hoffmann, B. Brutschy, Y. V. Mironov, K. A. Brylev, and V. E. Fedorov (2010). Chem. Asian J. 5, 2507.

144. C. Echeverria, A. Becerra, F. Nunez-Villena, A. Munoz-Castro, J. Stehberg, Z. Zheng, R. Arratia-Perez, F. Simon, and R. Ramirez-Tagle (2012). New J. Chem. 36, 927.

145. Y. Yamauchi, J. Imasu, Y. Kuroda, K. Kuroda, and Y. Sakka (2009). J. Mater. Chem. 19, 1964.

146. L. Tang, and J. J. Cheng (2013). Nano Today 8, 290.

147. J. L. Yan, M. C. Estevez, J. E. Smith, K. M. Wang, X. X. He, L. Wang, and W. H. Tan (2007). Nano Today 2, 44.

148. F. Grasset, F. Dorson, S. Cordier, Y. Molard, C. Perrin, A. M. Marie, T. Sasaki, H. Haneda, Y. Bando, and M. Mortier (2008). Adv. Mater. 20, 143.

149. J. F. Dechezelles, T. Aubert, F. Grasset, S. Cordier, C. Barthou, C. Schwob, A. Maitre, R. A. L. Vallee, H. Cramail, and S. Ravaine (2010). Phys. Chem. Chem. Phys. 12, 11993.

150. T. Aubert, F. Cabello-Hurtado, M. A. Esnault, C. Neaime, D. Lebret-Chauvel, S. Jeanne, P. Pellen, C. Roiland, L. Le Polles, N. Saito, K. Kimoto, H. Haneda, N. Ohashi, F. Grasset, and S. Cordier (2013). J. Phys. Chem. C 117, 20154.

151. T. Aubert, N. Nerambourg, N. Saito, H. Haneda, N. Ohashi, M. Mortier, S. Cordier, and F. Grasset (2013). Part. Part. Syst. Charact. 30, 90.

152. F. Grasset, F. Dorson, Y. Molard, S. Cordier, V. Demange, C. Perrin, V. Marchi-Artzner, and H. Haneda (2008). Chem. Commun., 4729.

153. N. Nerambourg, T. Aubert, C. Neaime, S. Cordier, M. Mortier, G. Patriarche, and F. Grasset (2014). J. Colloid Interface Sci. 424, 132. 